\title{
A Review on Micro- and Nanoscratching/Tribology at High Temperatures: Instrumentation and Experimentation
}

\author{
Saeed Zare Chavoshi (D) and Shuozhi Xu (D)
}

\author{
(Submitted December 12, 2017; in revised form May 4, 2018; published online July 5, 2018)
}

\begin{abstract}
High-temperature micro-/nanomechanics has attracted much interest over the last decade, primarily because of the urgent need to understand the mechanical and tribological properties of advanced engineering materials at micro-/nanoscale and the underlying physics controlling such properties at operationally relevant conditions. Recent years have subsequently witnessed the swift growth and development of new high-temperature micro- and nanoscratching/tribology instruments. Here, we present an overview of fundamental principles and developments in these instruments, discuss pertinent findings on the topic in detail, and outline current challenges and promising future directions in the field.
\end{abstract}

Keywords high temperature, micro-/nanoscale, scratching, tribology

\section{Introduction}

Scratching involves pulling an indenter along the material surface under a fixed or ramped load. Based on the applied load $L$ and the indenter radius $R$, micro-scratching tests are characterized by $\mathrm{mN}<L<30 \mathrm{~N}$ and $25 \mu \mathrm{m}<R<100$ $\mu \mathrm{m}$, whereas in nanoscratching $L$ ranges between $10 \mu \mathrm{N}$ and a few $\mathrm{mN}$, while $1 \mu \mathrm{m}<R<25 \mu \mathrm{m}$. Micro-/nanoscratching is a useful technique that can be employed to evaluate elastic recoverability and tribological performance, e.g., frictional and wear properties as well as resistance or mechanical failure modes of the thin films and functional coatings used in micro-/nanoelectromechanical systems (MEMS/NEMS) operating in physical contact mode (Ref 1-3). Particularly, some restrictions of atomic force microscopy (AFM), i.e., excessive tip wear on hard samples and measurement stability, can be overcome using nanoscratch testing. This technique therefore is regarded as a key tool for simulating single asperity contact in tribological experiments (Ref 4). The micro-/nanoscratching technique can also be adopted to provide extensive insight into the mechanical response and plastic deformation of materials. This method, unlike indentation, is a deviatoric stress-dominative process, carrying a noticeable component of shear, which leads to initiation of multiple plasticity mechanisms which may be different from those during indentation (Ref 5-10).

The application of small-scale materials is not restricted to room temperature. MEMS/NEMS are frequently employed at elevated temperatures, at which the tribological behavior and deformation physics are different owing to the increased

Saeed Zare Chavoshi, Department of Mechanical Engineering, Imperial College London, London SW7 2AZ, UK; Shuozhi Xu, California NanoSystems Institute, University of California, Santa Barbara, Santa Barbara, CA 93106-6105, USA. Contact e-mail: s.zare@imperial.ac.uk. activities of phonons (in crystalline insulators and some semiconductors), electrons (in metal and some semiconductors), propagons, diffusons, and locons (in amorphous nonmetallic materials), as well as thermal activation and phase transition processes (Ref 11). Specifically, wear at high temperature is of major concern at service temperatures and conditions relevant to industrial applications, and there is a need for a deeper understanding of the physics of friction at high temperatures when the sliding materials approach their melting points. Consequently, high-temperature testing of the small-scale materials has strongly motivated the development of new instruments and experimental protocols for hightemperature micro-/nanoscratching.

In this article, we intend to systematically describe the key concepts and recent developments in instrumentation and experimentation of high-temperature micro- and nanoscratching/tribology so as to provide an in-depth understanding and deliver a solid groundwork for future research into this topic. Overview of the modeling/theoretical aspects of tribology across scales (Ref 12) and at high temperatures (Ref 13) has been provided somewhere else; thus, it is out of the scope of the current contribution. We remark that the subject of micro- and nanoscratching/tribology at high temperatures is currently at the infancy stage and the extant literature in this field is relatively scarce. However, this arena is progressing at a very fast pace which could present numerous unresolved issues and challenges, as well as offer great opportunities for future study. We hope this article can inspire further experimental research in this crucial field of research.

\section{Instrumentation}

Scratching and tribology experiments are normally performed using both indentation and tribometer systems. The instrumented micro-/nanoindentation technique is generally used for the measurement of indentation/scratch hardness, elastic modulus, wear resistance, adhesion strength, coefficient of friction, mechanical failure and plastic deformation modes, as well as some other mechanical parameters such as 
micro-/nanofracture toughness and micro-/nanofatigue. The instrumented micro-/nanoindentation systems offer high levels of control, sensitivity, and data acquisition, which have led to the momentous progresses in fundamental mechanisms of mechanical and tribological behavior at micro- and submicrometer length scales. Various review articles have been published which form the basis of the principles of the instrumented room temperature indentation and scratching techniques and summarize the present state of understanding (Ref 4, 14-24). However, as noted in the previous section, the use of small-scale materials is not restricted to room temperature. MEMS/NEMS are often employed at elevated temperatures. Consequently, high-temperature testing of the smallscale materials is inevitable, inspiring the development of new testing methods, i.e., instrumented high-temperature micro-/nanoindentation.

There exists a history of application of "hot hardness" micro-indentation experiments, starting with Atkins and Tabor in 1966 (Ref 25). Nonetheless, instrumented hardness tests at high temperatures have a shorter history. The concept of hightemperature nanoindentation/scratching was first introduced in 1994-1995 by Oliver and co-workers who adopted a depthsensing indentation system capable of performing experiments between -100 and $300{ }^{\circ} \mathrm{C}$ in ultrahigh vacuum (Ref 26) and by placing a commercial nanoindenter in a temperaturecontrolled room up to $34{ }^{\circ} \mathrm{C}$ in order to test amorphous selenium (Se) (Ref 27). In 1996, Suzuki and Ohmura (Ref 28) developed a prototype of high-temperature indentation instrument, which was used to test $\mathrm{Si}$ single crystal up to $600{ }^{\circ} \mathrm{C}$. One year later, Syed Asif and Pethica (Ref 29) employed thermoelectric Peltier cells on both indenter and high purity Indium (In) sample sides to implement stable experiment at slightly colder or warmer temperatures than room temperature. In 2000, the MicroMaterials Ltd. (MML) NanoTest system was introduced by Smith and Zheng (Ref 30) who adopted a horizontal pendulum protected by a heat shield, and used independent resistive heaters and control thermocouples for both indenter and sample. Since then, several developments and modifications have been made to the high-temperature microand nanoindentation/scratching instrumentations and some of them are commercially available from different manufacturers, i.e., Alemnis system, ${ }^{*}$ MML NanoTest systems, ${ }^{* *}, \dagger$ Nanomechanics Inc. (NMI) system, ${ }^{*}$ Hysitron system, ${ }^{\S} \S \S$ SURFACE $\mathrm{GmbH}_{\text {laser-based heating }}{ }^{\&}$ for a Keysight system ${ }^{\& \&}$. These high-temperature nanoindentation machines are commonly employed to perform high-temperature micro-/nanoscratching trials. It should be mentioned that the experimental configuration of these systems is different from each other, leading to different levels of stability and reliability of the test data and the peak temperatures reachable. Table 1 summarizes the distin-

\footnotetext{
*http://alemnis.com/products/high-temperature-module/.

**http://www.micromaterials.co.uk/products/nanotest-vantage/.

${ }^{\dagger} \mathrm{http}: / /$ www.micromaterials.co.uk/products/nanotest-xtreme/.

thttp://nanomechanicsinc.com/insem-systems-page/.

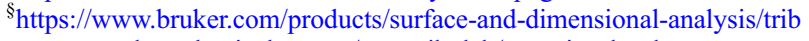
ometers-and-mechanical-testers/umt-tribolab/overview.html.

$\S \S_{\text {https: }} / /$ www.bruker.com/products/surface-and-dimensional-analysis/nano mechanical-test-instruments/standalone-nanomechanical-test-instruments/ ti-980-triboindenter/overview.html.

${ }^{\&}$ http://www.surface-tec.com/nanolaserheater.php.

${ }^{\& \&}$ http://www.keysight.com/en/pc-1678689/nanoindenters?cc=GB\&lc=eng.
}

guishing features of some popular instrumentations which can be used for high-temperature micro-/nanoscratching trials.

Common challenges and issues in micro- and nanoscratching/tribology at high temperatures are summarized in Fig. 1. In the following, we elaborate on these issues and discuss pertinent solutions.

Fundamentally, in high-temperature micro-/nanoscratching, oxidation should be eliminated or minimized. Several mitigating solutions to atmospheric issues exist. In micro-/nanoscratching at lower temperatures, i.e., $<200{ }^{\circ} \mathrm{C}$, oxidationproof coating could be applied on the surface of substrate. This approach has been successfully used for nanoindentation of $\mathrm{Cu}$ at $130{ }^{\circ} \mathrm{C}$ via platinum $(\mathrm{Pt})$ coating (Ref 31$)$. An overpressure of the shield gas, e.g., high purity argon or argon with hydrogen, could also be utilized to protect the hot zone during testing (Ref 32). Although inert atmospheres could be adequate for mildly reactive materials, a shielding liquid, viz. vacuum oil can be applied in some systems at moderately elevated temperatures to immerse the sample and avoid exposure to atmosphere. Hodge and co-workers (Ref 33) proposed a standardized method for vacuum oil as a protective medium, as shown in Fig. 2(a), where the protective liquid, Invoil 705 silicone-based vacuum oil, is injected into the container before testing, until the oil is about $1 \mathrm{~mm}$ higher than the sample height but lower than the container height. A representative result of thermal drift rate from tungsten (W) (100) at room temperature and $200{ }^{\circ} \mathrm{C}$ using oil as protective medium is demonstrated in Fig. 2(b), signifying acceptable drift rates.

In general, oxidation is most effectively minimized by removing the atmosphere completely and conducting tests in a vacuum environment, where continuous evacuation of the test chamber can offer improved protection from oxidation or contamination. MML NanoTest Xtreme nanoindentation system can be a good solution. Notice that the introduction of a vacuum or inert gas inevitably changes thermal transport in the system and thus can impact thermal drift and noise during testing as well (Ref 34,35$)$. In fact, a key consideration in hightemperature micro-/nanoscratching is the successful achievement of a stable, isothermal indentation contact at a known temperature in thermal equilibrium. The most effective way is to heat up both the indenter and the sample independently. Finite element (FE) analysis of thermal conductivity of hightemperature nanoindentation has shown that the indenter/ sample system can reach a thermal equilibrium fairly swiftly; however, the nanoindenter cannot reach the same temperature as the bulk sample, even for samples with high thermal conductivity (Ref 36). In low conductivity materials, e.g., fuse silica (FS), the thermal gradient underneath the nanoindenter tip is somewhat diffuse, whereas in high conductivity materials, e.g., Au, most of the sample can equilibrate at the set temperature, resulting in a very steep thermal gradient immediately beneath the indenter. Nanoindentation experiments using an $\mathrm{cBN}$ Berkovich indenter on both $\mathrm{FS}$, at temperatures up to $600{ }^{\circ} \mathrm{C}$, and annealed $\mathrm{Au}$ at temperatures up to $300{ }^{\circ} \mathrm{C}$ have also shown that nanoindentation without independent indenter and sample heating generates undesirable thermal perturbation in the system (Ref 36). Schuh and co-workers (Ref 37) also corroborated similar findings when they investigated the technical issues related to high-temperature nanoindentation measurements in vacuum using FE simulations. Their study supported proposals such as independent heating of indenter and sample, use of gas atmosphere to reach an acceptable thermal equilibrium, and use of a tip assembly with very low or 
Table 1 Primary features of popular commercially available high-temperature instrumentations

Instrumentation

Hysitron TI 980

NMI InSEM HT

MML NanoTest Vantage

MML NanoTest Xtreme

Alemnis

Hysitron UMT TriboLab
Characteristics

Vertical loading setup; testing temperatures up to $800{ }^{\circ} \mathrm{C}$ and beyond using xSol high-temperature stage (a)

Horizontal loading setup; independent indenter and sample heating system; testing temperatures up to $800{ }^{\circ} \mathrm{C}$

Horizontal loading setup; capable of performing tests under reduced oxygen/purged condition and controlled humidity levels up to testing temperatures of $500{ }^{\circ} \mathrm{C}$ and beyond; independent indenter and sample heating system

Similar to MML NanoTest Vantage, yet capable of conducting tests under vacuum (up to $10^{-7}$ mbar) up to $950{ }^{\circ} \mathrm{C}$

Horizontal loading setup; testing temperature up to $600{ }^{\circ} \mathrm{C}$ using high-temperature module; compatible for in situ use with scanning electron microscopes (SEM); true displacement controlled mode

Heating chamber up to $1000{ }^{\circ} \mathrm{C}$ and controlled humidity

(a) https://www.hysitron.com/products-services/options-upgrades/xsol-high-temperature-stage

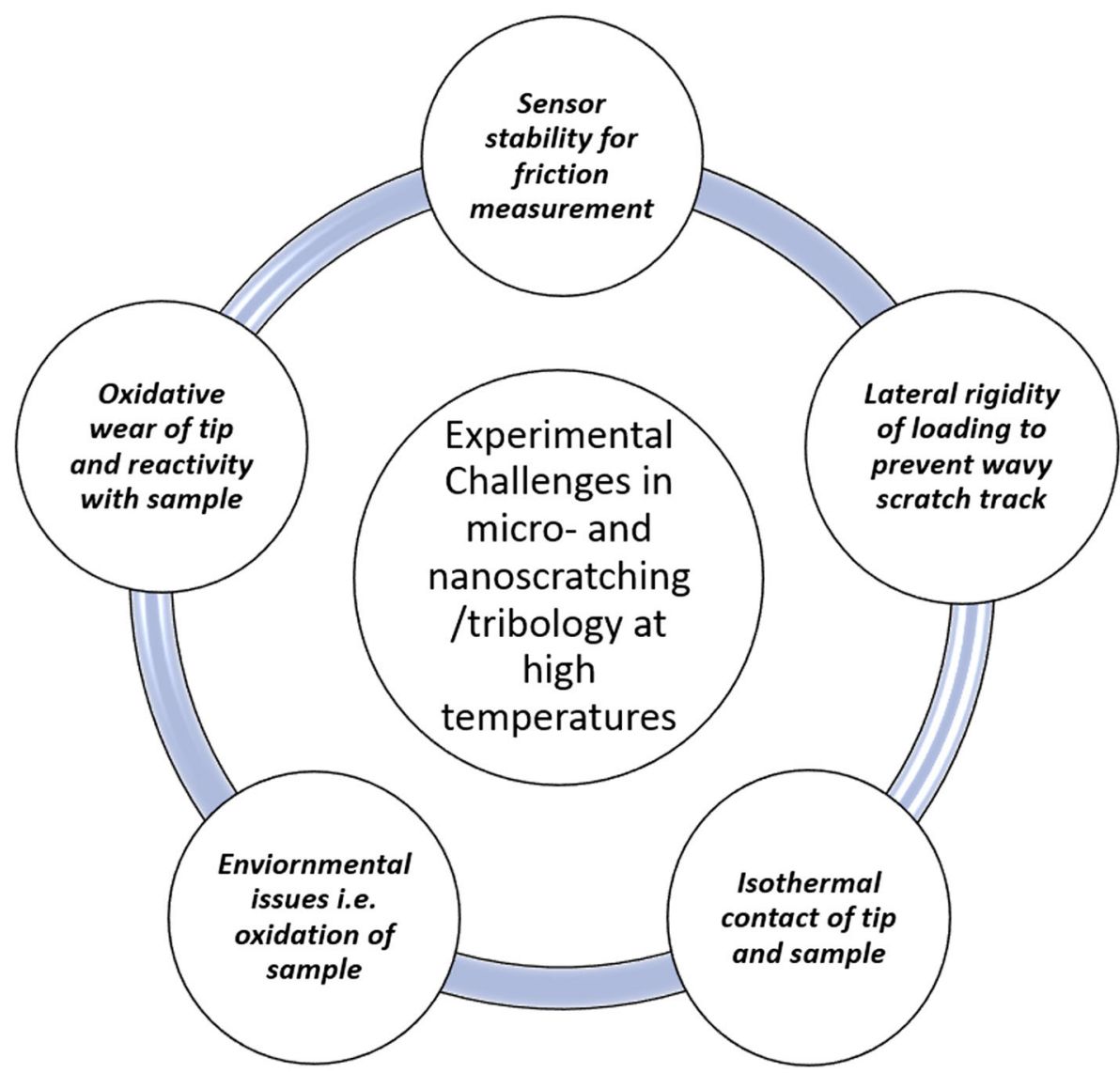

Fig. 1 Experimental challenges faced in micro- and nanoscratching/tribology at high temperatures

zero thermal expansion coefficient to suppress artificial drift displacements.

An effective method to achieve a stable, isothermal contact at a known temperature in thermal equilibrium is to use the indenter temperature profile during the process as a sensitive and unique signature of the system thermal setup (Ref 38). A practical step-by-step guidance for this method has been recently suggested by Hou et al. (Ref 39) and can be used to achieve an isothermal contact at a known temperature. More information on procedures for satisfying requirements of oxidation elimination and thermal management can be found in the works by Wheeler and his colleagues (Ref 35, 38, 40) and those presented by Schuh and co-workers (Ref 32, 41-43). Note that at high temperatures, the thermocouple/indenter materials could react and damage the indenter; thus, care has to be taken in choosing the thermocouple type to avoid this problem.

If the purpose of the testing is the friction measurement, care should also be taken in attaining adequate sensor stability at elevated temperatures. A solid-state piezoresistive force trans- 


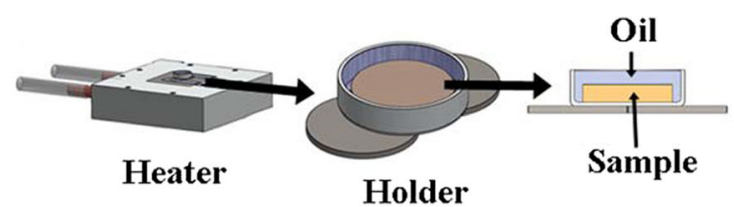

(a)

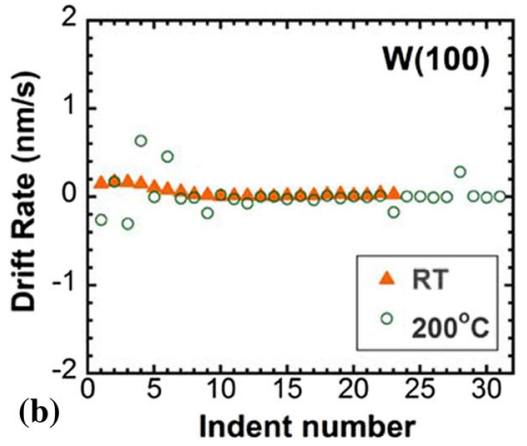

Fig. 2 (a) Schematic illustration of the sample holder and heating stage used by Hodge and co-workers to apply vacuum oil as a protective medium during high-temperature nanoindentation, (b) a representative result of thermal drift rate from W (100) at room temperature (RT) and $200{ }^{\circ} \mathrm{C}$ using oil as a protective medium. (Reprinted with permission from Ref 33 )

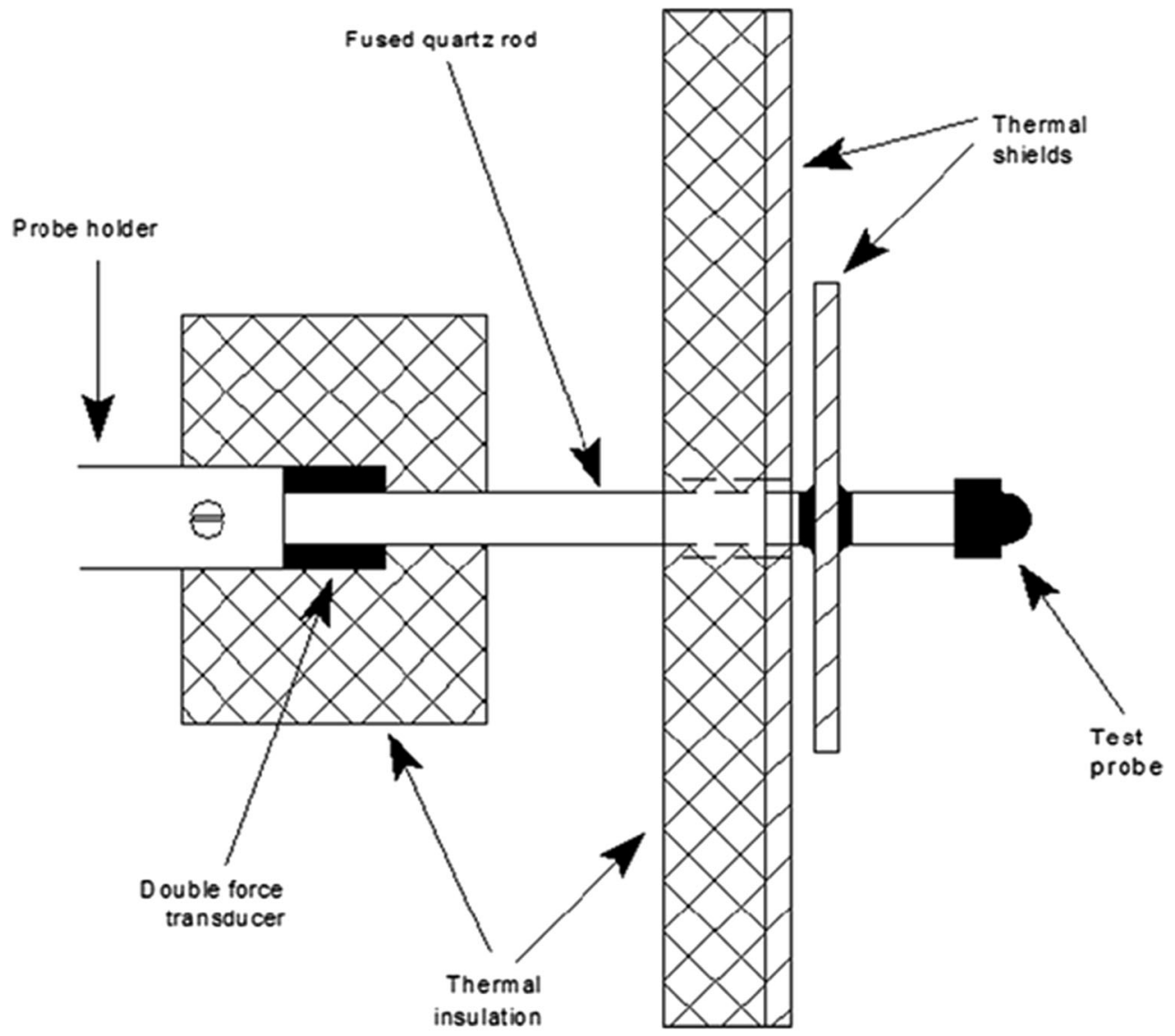

Fig. 3 Instrument hardware for friction measurements at high temperatures. (Reprinted with permission from Ref 44)

ducer made of doped silicon $(\mathrm{Si})$ is usually employed for friction measurements at room temperature. With some modifications, the same transducer can be used for friction measurements at high temperatures. Figure 3 illustrates a schematic diagram of a modified instrument hardware which can be used for high-temperature friction measurements. In this configuration, a fused quartz rod having low expansion coefficient and low thermal conductivity separates the hot test probe from the force transducers. This rod also serves as a thermal barrier which minimizes heat conduction from the contact area leading to the establishment of a thermal equilibrium. The transducers are bonded to one end of the rod, and the test probe is bonded to the other using ceramic cement. The transducer housing is located behind the instrument's normal heat shield, and an additional concentric heat shield is supported on the fused quartz rod to further protect the sensor. Friction coefficients $(\mu)$ can be determined according to Amontons' law, i.e., $\mu=F_{\mathrm{t}} / F_{\mathrm{n}}$ where $F_{\mathrm{t}}$ and $F_{\mathrm{n}}$ are tangential and normal forces, respectively (Ref 44).

Recently, a test rig has been developed at the Austrian competence center for tribology which permits carrying out hardness and scratch tests up to $1000{ }^{\circ} \mathrm{C}$ using loads up to $500 \mathrm{~N}$ under protective vacuum atmosphere $(<5$ mbar $)$ to prevent oxidation of the samples. A schematic of this test rig is 


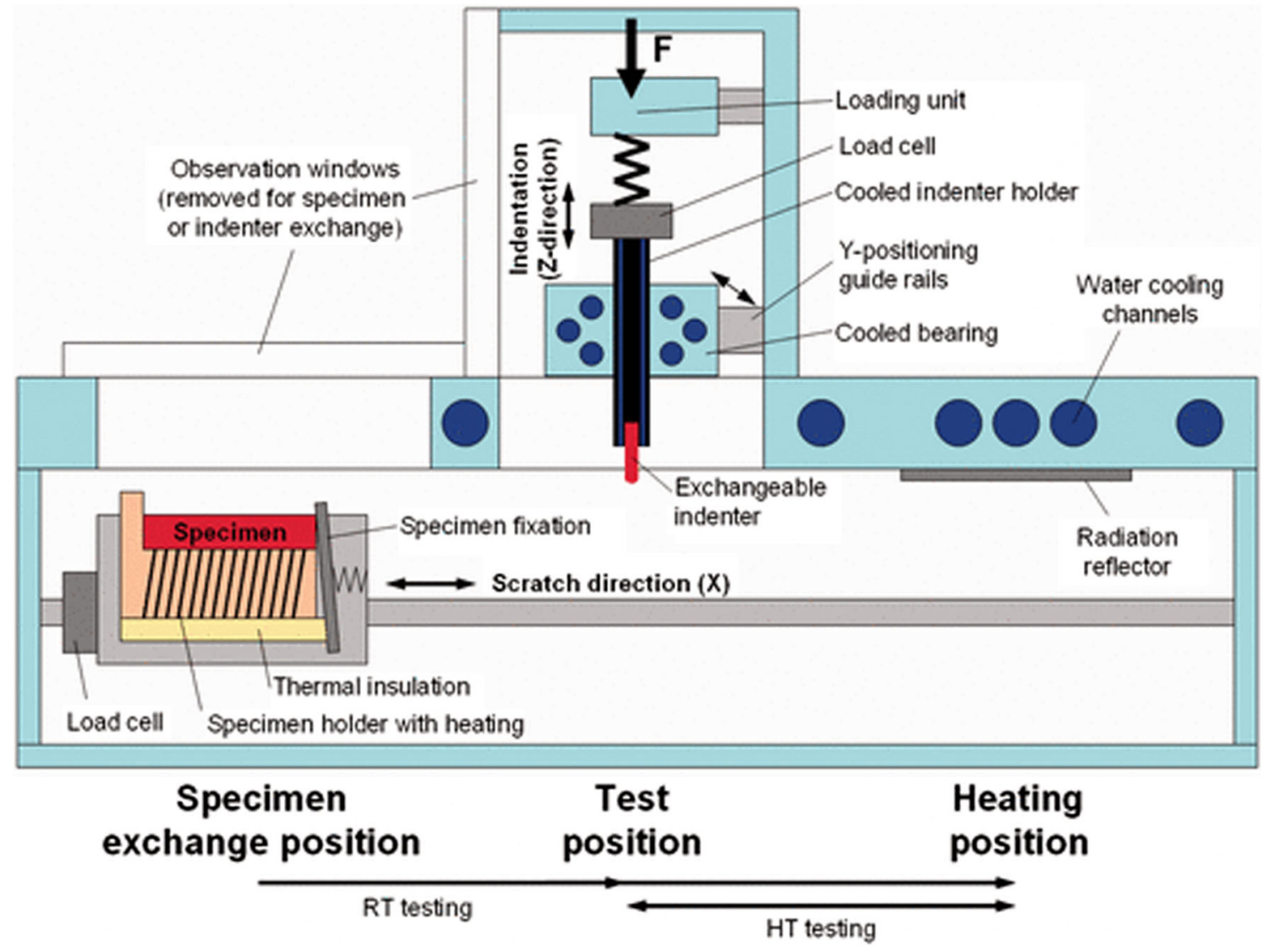

Fig. 4 Side view of the high-temperature scratch test rig developed at the Austrian competence center for tribology. (Reprinted with permission from Ref 46)

demonstrated in Fig. 4. The test rig is formed by a loading unit and a sample holder which move in the vertical and horizontal directions, respectively. Once the desired load is reached, the sample holder moves horizontally, producing a scratch under load-controlled conditions (Ref 45).

It should be noted here that some of the modified nanoindentation machines are more suitable for nanotribological tests due to their high lateral rigidity which prevents wavy scratch tracks on rough samples. The flexures used in the MML NanoTest system and the National Physical Laboratory (NPL) micro-/nanotribometer make them excellent systems for nanotribological experiments. Figure 5 shows the tribometer designed in NPL in the UK which can be used to carry out micro-/nanoscale tribological experiments on the laboratory bench as well as in situ in an SEM. The key feature of the rig is a flexure element with the probe (diamond indenter) at the end (Ref 47). The flexure element supports the probe, restricts the motion of the probe to the two required orthogonal directions, generates the applied normal force, and measures friction (Ref 48, 49).

In high-temperature micro-/nanoscratching, indenters often encounter extreme thermal and mechanical stresses which could result in plastic deformation and accelerated wear of the indenter. Accordingly, care must be taken to choose indenter material possessing and maintaining high hardness at high temperatures. Diamond, cubic boron nitride (cBN), and boron carbide $\left(\mathrm{B}_{4} \mathrm{C}\right)$ can be reliable choices of the indenter material for high-temperature studies. Polycrystalline, sintered boride ceramics such as zirconium diboride $\left(\mathrm{ZrB}_{2}\right)$, titanium diboride $\left(\mathrm{TiB}_{2}\right)$, hafnium diboride $\left(\mathrm{HfB}_{2}\right)$, and aggregated diamond nanorods could also be used as indenter materials for high-temperature applications. However, more data on their single crystals, their material properties at elevated temperatures and availability are required to determine their suitability for such applications. Another critical issue regarding the indenter material, apart from a high hardness value, is the chemical reactivity of the indenter with atmosphere at high temperatures which causes oxidative damage as well as the indenter/substrate reactivity leading to excessive wear rates. Some safe temperature regimes and indenter/substrate material combinations for high-temperature indentation/scratching have been provided by Wheeler and Michler (Ref 50), which can be used as a guideline for performing trials. Note that, although diamond is the hardest material, oxidative wear of diamond at $>400{ }^{\circ} \mathrm{C}$ in nonvacuum systems and diamond's tendency to react with ferrous or carbide-forming early transition metals restrict its applicability. cBN, tungsten carbide (WC), and sapphire are more suitable in the cases where diamond is likely to unfavorably react with the substrate material at elevated temperatures. In particular, $\mathrm{cBN}$ and sapphire tips are popular, even though they are much softer than diamond, because of their reactivity, immunity to oxidation, low cost, and good machinability (Ref 35,51 ). 


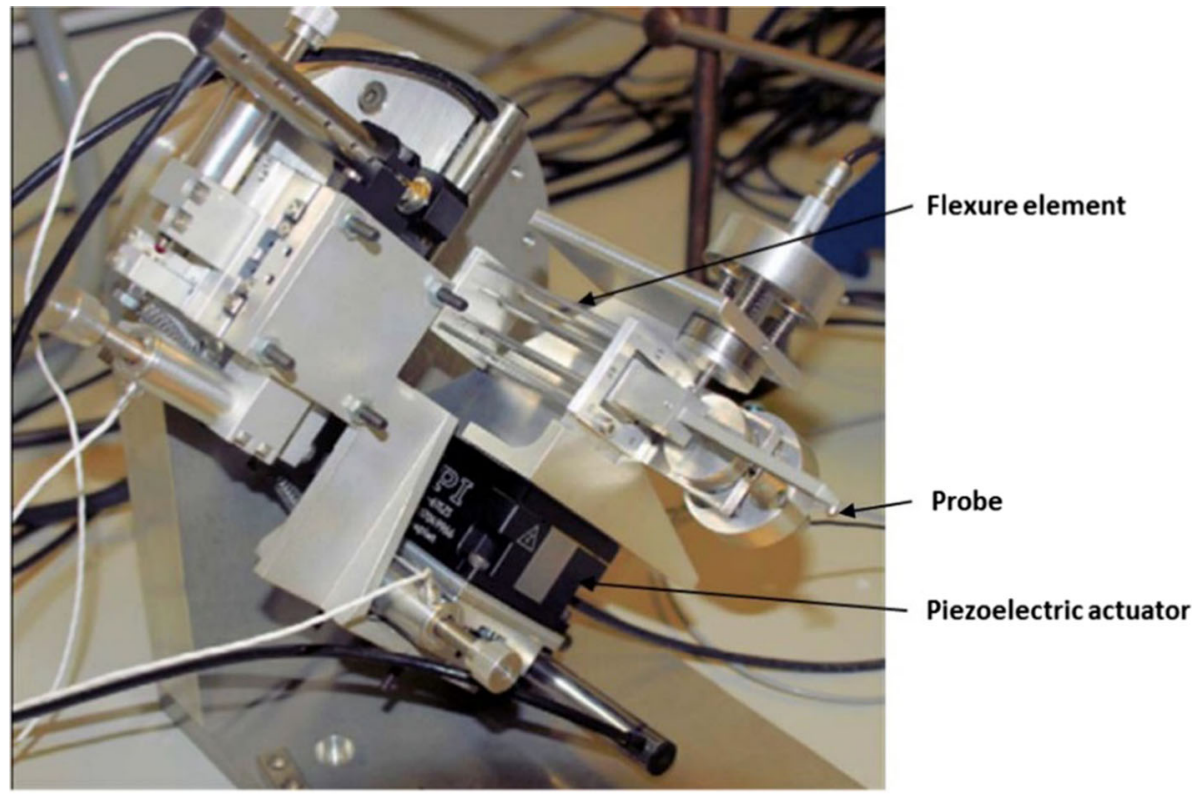

(a)

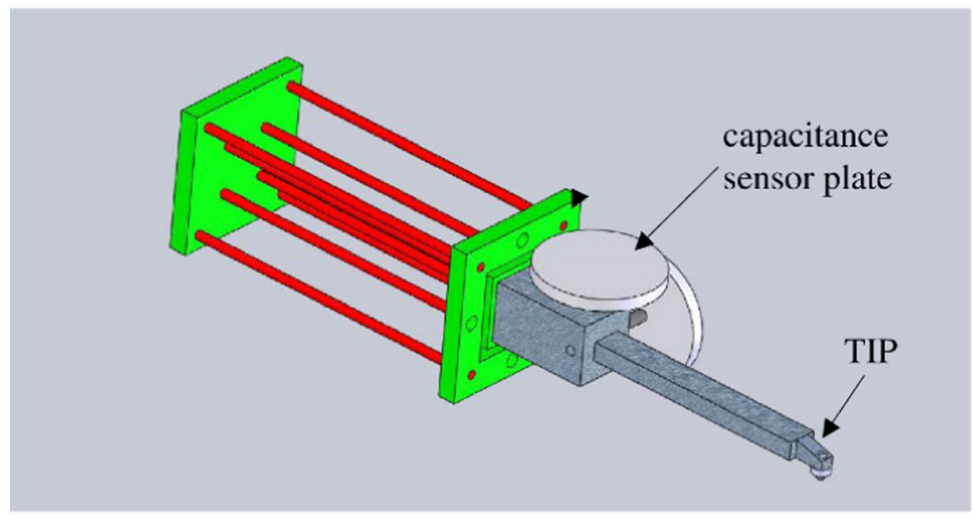

(b)

Fig. 5 (a) Micro-tribometer developed at NPL in the UK, (b) schematic of the flexure element. (Reprinted with permission from Ref 48, 49)

\section{Micro-/Nanoscratching Response of Materials at High Temperatures}

A search of the literature on the high-temperature micro-/nanoscratching has yielded a few results. However, these studies bring forth important physical insights regarding inherent mechanical properties, underlying physics, and deformation propensity of materials at elevated temperatures. Consequently, micro-/nanoscratching at high temperatures is indeed a fruitful avenue for further research. Table 2 summarizes some interesting findings on the scratching/tribology responses of different materials at high temperatures. In this section and section 4, we discuss these findings in detail.

A recent study on high-temperature nanoscratching of $\mathrm{Si}(110)$ wafer using ramped loading under argon gas purged condition shows that temperature significantly affects the residual scratch morphologies, viz. scratch depth, scratch width, and total pile-up heights increase with increasing substrate temperature, attributable to the thermal softening processes. Moreover, scratch hardness $\left(H_{\mathrm{s}}\right)$ decreases with increasing temperature owing to an effective decrease in the shear stress. $H_{\mathrm{s}}$ of $\mathrm{Si}$ and steel alloys increases with scratching speed, suggesting that strain rate strengthening occurs at higher scratching speeds (Ref 52,64$)$. Notice that $H_{\mathrm{s}}$ can be used to determine the resistance of a material to the scratch, and it is described as the response of the material under dynamic deformation of the surface. $H_{\mathrm{s}}$ is defined as the ratio of the vertical load $(P)$ to the surface area of the tip-sample contact or the contact area projection onto the horizontal plane which depends on the residual scratch width $(b)$ :

$H_{\mathrm{s}}=k \frac{P}{b^{2}}$

where $k$ is the nanoindenter tip shape factor, which is dependent on the tip configuration. For a Berkovich indenter, this factor is 2.31 (Ref 65).

It is instructive to mention that indentation and scratch hardness can be regarded as an extrinsic property of the material, meaning that the indenter shape, the mode of load 
Table 2 Overview of scratching/tribology responses of different materials at high temperatures

Material

Single crystalline $\mathrm{Si}$

PVD AlCrN

AlCrN, AlTiN, TiCN

$\operatorname{AlCrV}(\mathrm{x}) \mathrm{N}$

Glass

$\mathrm{TiFe}_{11} \mathrm{Mo}_{14} \mathrm{~N}_{45}$

$\mathrm{Ti}_{24} \mathrm{Fe}_{15} \mathrm{Mo}_{11} \mathrm{~N}_{46} \mathrm{O}_{4}$

$\mathrm{Cr}_{2} \mathrm{AlC}, \mathrm{TiFeMoN}, \mathrm{TiN}, \mathrm{TiFeMoN}, \mathrm{TiFeN}$

Austenite, Ferritic MMCs and Ni-based MMCs

Ag-Bi alloy
Primary characteristics

Decrease in scratch hardness up to $46 \%$ with increasing temperature from room temperature to $500{ }^{\circ} \mathrm{C}$; increase in residual scratch morphologies with increasing temperature; absence of high-pressure Si phases in nanoscratch tracks at $500{ }^{\circ} \mathrm{C}$ (Ref 52); decrease in surface roughness of wafers processed by micro-laser assisted machining ( $\mu$-LAM) (Ref 53)

Reduction in failure load with the increase in temperature (Ref 54); decrease in relative performance improvement provided by substrate nitriding at high temperatures (Ref 54-56)

Increase in failure load and scratch crack propagation resistance (CPR) with the increasing temperature, plausibly owing to application of a hard material, i.e., cemented carbide as the substrate (Ref 57-59)

Less pronounced alternation of friction while increasing temperature up to $400{ }^{\circ} \mathrm{C}$; decrease in the friction coefficient at $700{ }^{\circ} \mathrm{C}$ with an increasing vanadium content, attributable to the oxidation and formation of Magnéli phases of the coatings with vanadium contents above 10.7 at.\% (Ref 60, 61)

Increase in friction up to $\sim 300 \%$ with increasing temperature from 25 to $200{ }^{\circ} \mathrm{C}$ (Ref 44)

Increase in friction up to $\sim 200 \%$ with increasing temperature from Room temperature to $200{ }^{\circ} \mathrm{C}$ (Ref 44$)$

Increase in friction up to $\sim 1500 \%$ with increasing temperature from room temperature to $400{ }^{\circ} \mathrm{C}$; sharp decrease in friction at $750{ }^{\circ} \mathrm{C}$ to approximately room temperature values (Ref 44)

Increase in surface roughness with increasing temperature (Ref 44)

Dominance of ploughing as the wear mechanism up to temperature of $500{ }^{\circ} \mathrm{C}$, which switches to cutting for the Ni-based $\mathrm{MMC}$ at $800{ }^{\circ} \mathrm{C}$ for high loads (Ref 62)

For 97.5 wt. $\% \mathrm{Bi}-2.5 \mathrm{wt} \% \mathrm{Ag}$ and $70 \mathrm{wt.} \% \mathrm{Bi}-30 \mathrm{wt} \% \mathrm{Ag}$, sharp decrease in friction at temperatures higher than the eutectic temperature; for $50 \mathrm{wt} \% \mathrm{Bi}$ 50 wt.\%Ag, constant increase in friction with increasing temperature (Ref 63)
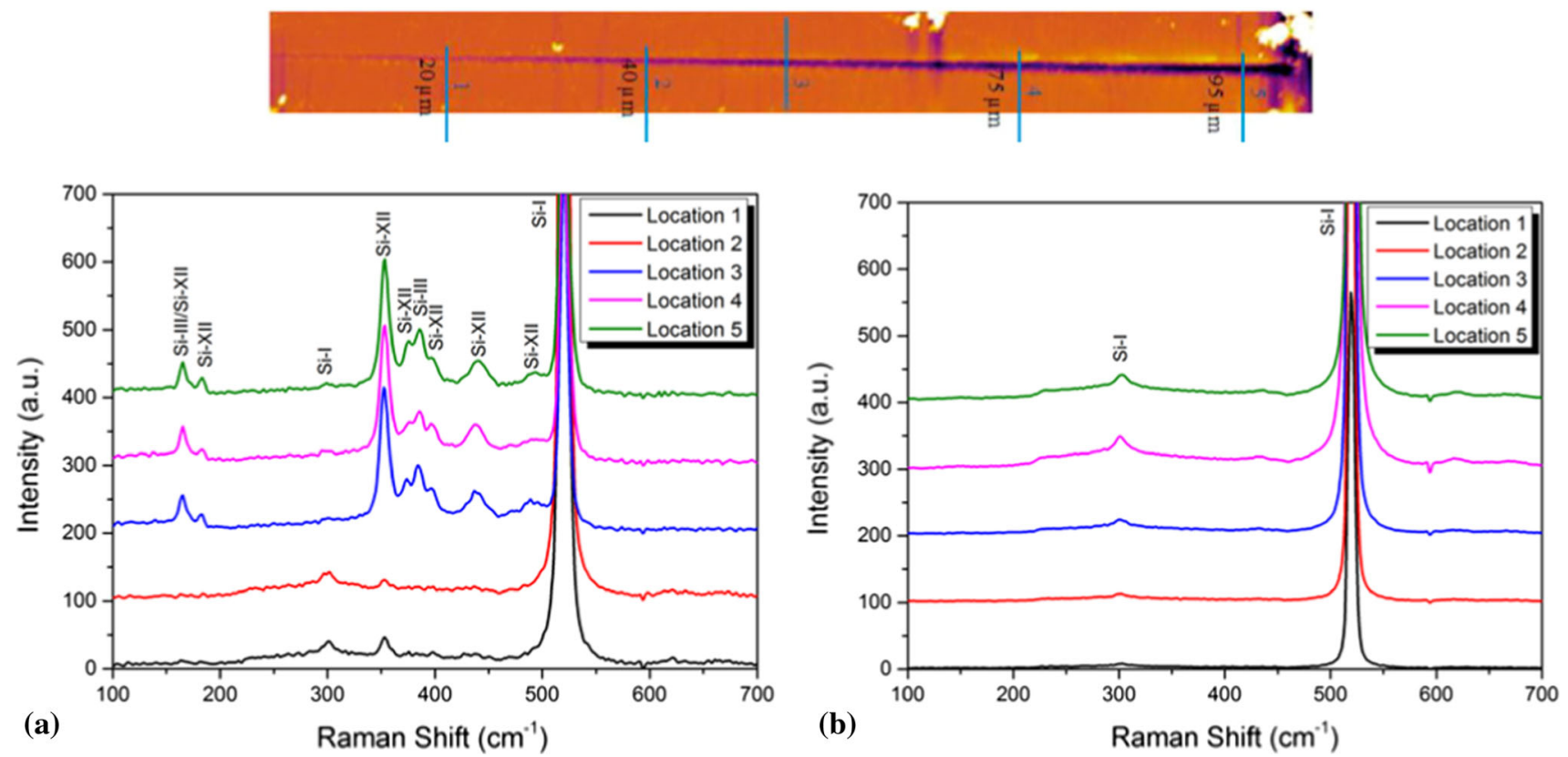

Fig. 6 Raman spectra collected from five different locations of the Si nanoscratch made at (a) room temperature, (b) high temperature of $500{ }^{\circ} \mathrm{C}$. High-pressure Si phases are not detected for the case of high-temperature nanoscratching. (Reprinted with permission from Ref 52)

application (static, scratch, impact), and the magnitude of the applied load, which determine the depth of penetration, can significantly affect the hardness. For instance, the scratch hardness of Ni-Co alloy can increase up to five times once the depth of penetration drops from the micrometer to the nanometer range (Ref 66).
Ex situ Raman spectroscopy results illustrated in Fig. 6(a) reveal that, while nanoscratching of $\mathrm{Si}$ at room temperature, phase transformation is notably dependent on the applied load and scratching speed. The nanoscratch track created at room temperature contains $\mathrm{Si}-\mathrm{I}, \mathrm{Si}-\mathrm{XII}$ and $\mathrm{Si}-\mathrm{III}$ phases above different threshold loads at low and high scratching speeds. 
On the contrary, as seen in Fig. 6(b), high-pressure Si phases are not visible for the case of nanoscratching at $500{ }^{\circ} \mathrm{C}$, signifying the transition of metastable $\mathrm{Si}$ phases (Si-III and SiXII) into thermodynamic stable Si-I (Ref 52). In fact, high temperatures can boost the transition of metastable Si phases (Si-III and Si-XII) into thermodynamically stable Si-I (Ref 67). The lifetime of the $\mathrm{Si}-\mathrm{III} / \mathrm{XII}$ is presumed to be temperaturedependent, i.e., at $320{ }^{\circ} \mathrm{C}$ and ambient pressure, it is over $1 \mathrm{~min}$, while in high power laser irradiation of the indentation imprints, it would be approximately $1 \mathrm{~s}$ (Ref 68, 69).

While using an ex situ Raman microscope, the structure and phases of the material are detected after the completion of the nanoscratching trials; thus, only remnant phases can be determined, which is the case for the aforementioned study. In order to probe the transformation path and existence of intermediate phases at high temperatures, the nanoindentation/ scratching machine should be coupled with a microscope so as to enable in situ Raman measurements. Raman spectroscopyenhanced instrumented indentation techniques have been recently developed at the National Institute of Standards and Technology (NIST) (Ref 70-74) and Hysitron, Inc., USA (Ref 75), which are capable of conducting in situ spectroscopic analyses of mechanically deformed regions of materials under contact loading at room temperature. These techniques might be further modified for in situ Raman measurements at high temperatures. Note that in situ SEM measurement techniques at high temperatures have already been developed and utilized by researchers (Ref 40, 76, 77). Generally, in situ high-temperature micro-/nanoscratching measurements allow the real-time exploratory work of the interplay between mechanical, tribological, thermal, and electrical effects at the micro-/nanoscale. This is an interesting area of further research which is encouraged for the future work.

From a manufacturing standpoint, high-temperature nanoscratching can be employed for the nanofabrication purposes, i.e., nanopatterning on semiconductor and ceramic wafers. Nanofabrication via mechanical scratching is regarded as a superior choice over other techniques since it provides a better control over the applied normal load, scan size, and scanning speed during the nanofabrication. In addition, application of chemical etching or reactions is not needed and this dry nanofabrication process can be employed where use of chemicals and electric field should be avoided. However, the formation of debris/chip during scratching can adversely affect the accuracy and surface finish of the fabricated components. For the light loads, debris can be simply removed from the scan area during scanning, yet this issue is more pronounced for high-load scratching (Ref 78). On the other hand, components used in micro-/nanosystems are usually fabricated from optical grade wafers. A series of precision machining processes, i.e., cutting, lapping, polishing, and chemical mechanical polishing are required to produce qualified wafers with sub-micrometer form accuracy and nanometer surface roughness. Single-point diamond turning (SPDT) is an ultraprecision machining process making use of a single crystalline diamond tool which possesses nanometric edge sharpness, form reproducibility, and wear resistance. The process is capable of producing components with micrometer to sub-micrometer form accuracy and surface roughness in the nanometer range (Ref 79). On the other hand, semiconductor and ceramic materials used in micro-/nanosystems are nominally hard and brittle, which stems from their covalent chemical bonding. Thus, these hardbrittle materials have poor machinability at room temperature due to their relatively low fracture toughness and high hardness. It has been demonstrated that ductile regime machining is possible due to the high-pressure phase transformation (HPPT) occurring in the semiconductor and ceramic materials caused by the high compressive and shear stresses induced by the single-point diamond tool tip (Ref 80-82). It is also known that yield strength and hardness of materials normally decrease with the increase in temperature. As such, the fracture toughness increases which in turn facilitates plastic deformation and ductile mode machining. In other words, at high temperatures, plasticity plays a greater role in the fracture and deformation processes primarily as a result of thermally generated defects and thermal softening processes (Ref 83, 84). Accordingly, to further augment the ductile response of hard-brittle materials, the machining process can be coupled with a heat source, e.g., laser (Ref 85-89). Recently, SPDT has been coupled with the $\mu$-LAM technique to preferentially heat and soften the high-pressure metallic phase during scratching/cutting. As seen in Fig. 7(a), a laser beam is transmitted through an optically transparent diamond (cutting tool) and focused precisely at the tool-workpiece interface, where the material is under high pressures induced by the diamond tool. The HPPT zone then absorbs the laser radiation to soften the material which leads to lower cutting forces. The experimental setup of SPDT coupled with the $\mu$-LAM is shown in Fig. 7(b). Figure 7(c) demonstrates that the Si (111) wafer machined by SPDT coupled with $\mu$-LAM possesses mirror-like surface finish $(\mathrm{Ra}=3.2 \mathrm{~nm})$ with no sign of surface damages (Ref 53).

\section{Micro-/Nanotribology at High Temperatures}

Micro-/nanotribological studies at high temperatures can provide useful information of high contact pressure sliding/ abrasive contacts at operationally relevant conditions. The hardness and modulus of most materials drop with the increase in temperature, which subsequently influences the mechanics of tribological interfaces (Ref 32). A recent study on hightemperature micro-scratching of physical vapor deposition (PVD) AlCrN coating deposited on tool steel in open atmosphere using a Bruker CETR UMT-2 multifunction tribometer, equipped with a high-temperature test chamber, and a WC blade reveals a reduction in failure load with increasing temperature (Ref 54). This contradicts the results obtained in former studies, where failure load and scratch crack propagation resistance (CPR) of $\mathrm{AlCrN}$, AlTiN, and TiCN coatings increased with increasing temperature (Ref 57-59), plausibly due to application of a hard material, i.e., cemented carbide as the substrate, which reduces thermal softening effects. However, critical load for TiAlN coatings deposited on cemented carbide decreases with temperature, which is different from the behavior of aforementioned coatings. This behavior can be attributed to the differences in interfacial stress distributions caused by changing mechanical properties with coating composition, contact stress, and temperature. AlTiN exhibits a higher critical load (onset of cracking load) compared to TiAlN and AlCrN coatings, which is not attributed to the former's high $H^{3} / E^{2}$ ( $H$ and $E$ are hardness and elastic modulus, respectively) but to its lower interfacial stresses, plastic flow in the coating, and reduced substrate deformation, especially at high temperatures, e.g., $500{ }^{\circ} \mathrm{C}$ (Ref 90). On the other hand, annealing reduces the critical load of AlTiN; 


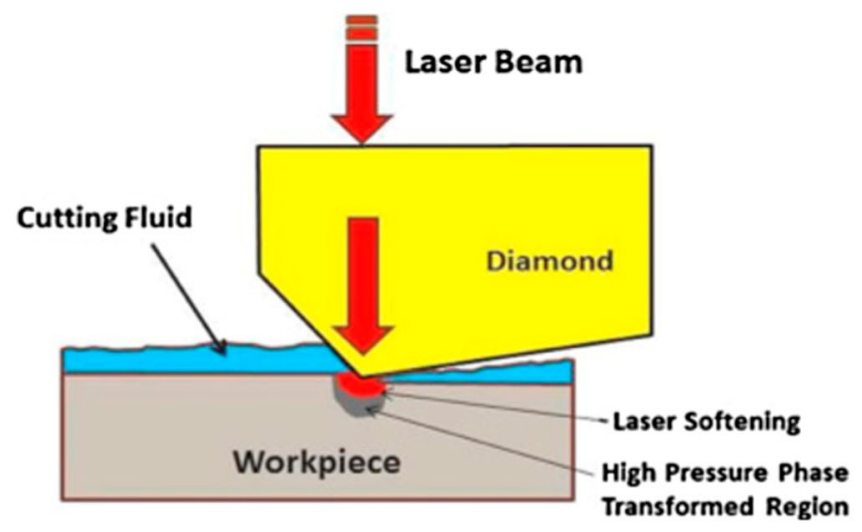

(a)

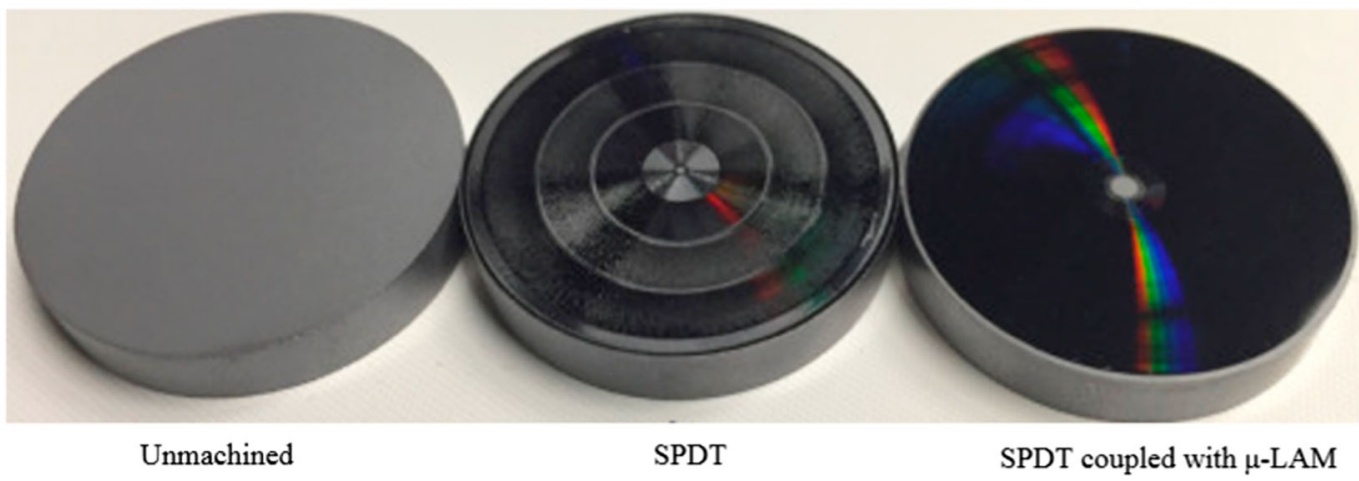

Fig. 7 (a) Schematic of the $\mu$-LAM process with cutting fluid, (b) $\mu$-LAM setup mounted on a diamond turning machine, (c) Si (111) wafer machined by SPDT coupled with $\mu$-LAM possesses mirror-like surface finish. (Reprinted with permission from Ref 53)
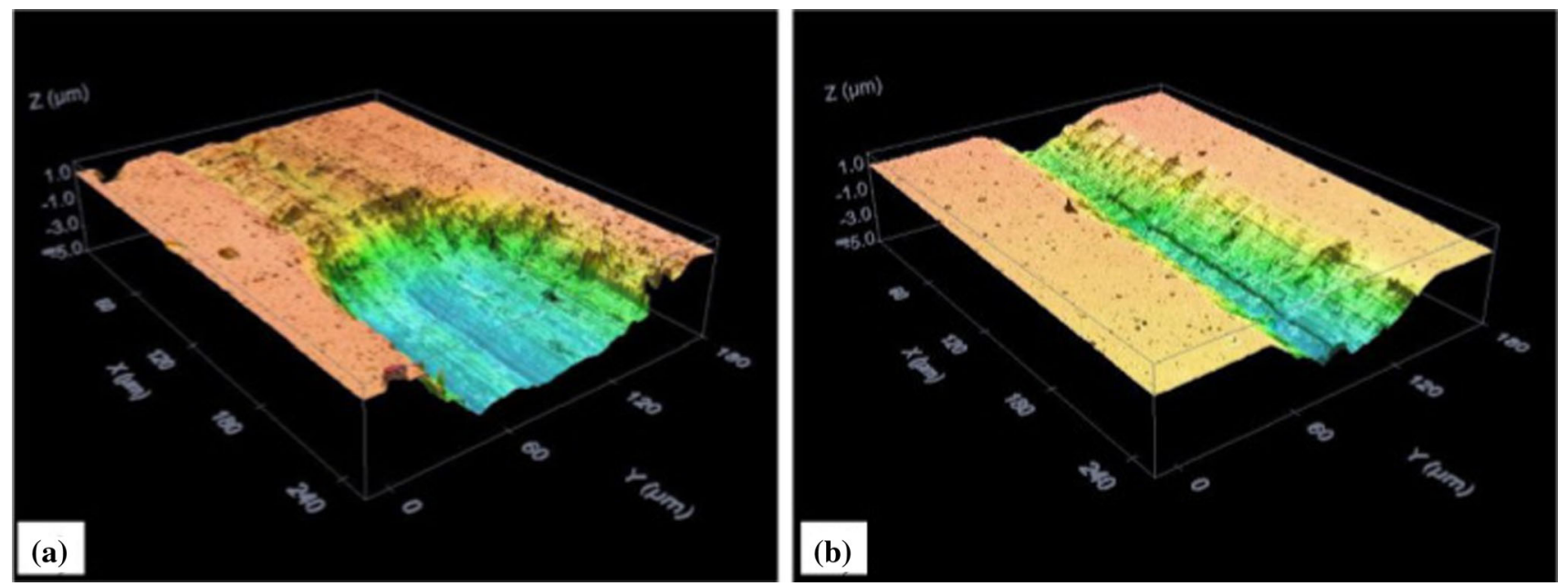

Fig. 8 Scratch tracks at failure load for PVD AlCrN at (a) room temperature $(8.8 \mathrm{~N})$ and (b) $500{ }^{\circ} \mathrm{C}(4 \mathrm{~N})$. (Reprinted with permission from Ref 54)

however, at high temperatures, the critical loads of as-deposited and annealed AlTiN are higher than those at room temperature (Ref 58). Analysis using confocal microscopy shown in Fig. 8 confirms that even before delamination, a severe plastic deformation occurs in high-temperature scratch testing, whereas at room temperature the failure is abrupt and indenter sinks into the substrate at the failure load. It is informative to mention that surface nitriding and presence of hard white layer can conspicuously improve the scratch resistance at room and high temperatures. Relative performance improvement provided by substrate nitriding, though decreasing at higher temperatures, remains remarkable (Ref 54-56).

Figure 9 demonstrates the variation of friction coefficient of magnetron sputtered $\mathrm{AlCrVN}$ thin films with different vanadium contents up to 13.5 at. $\%$ at room temperature, 400 and $700{ }^{\circ} \mathrm{C}$, obtained using a high-temperature ball-on-disk tri- 


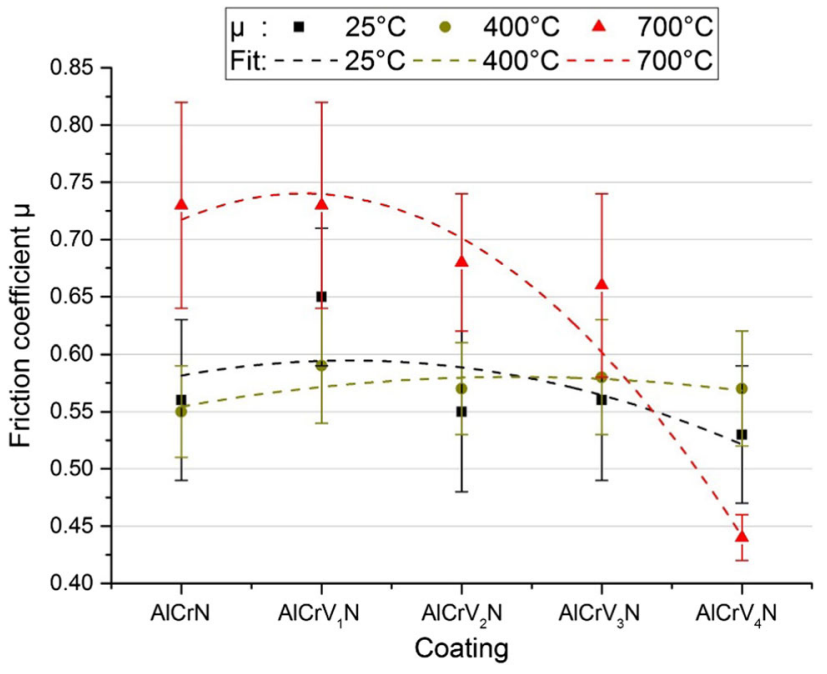

Fig. 9 Variation of friction coefficient of $\mathrm{AlCrVN}$ thin films at different temperatures. $\mathrm{AlCrV}_{1} \mathrm{~N}, \mathrm{AlCrV}_{2} \mathrm{~N}, \mathrm{AlCrV}_{3} \mathrm{~N}$, and $\mathrm{AlCrV}_{4} \mathrm{~N}$ have the vanadium content of $3.4,7.1,10.7$, and 13.5 at.\%, respectively. (Reprinted with permission from Ref 60)

bometer (CSM-Instruments) with a $100 \mathrm{Cr} 6$ ball. It is evident that friction properties of $\mathrm{AlCrN}$ thin films can be improved by incorporation of vanadium. Friction coefficient decreases with the increase in vanadium content, which is primarily caused by the oxidation and formation of Magnéli phases of the coatings with vanadium contents above 10.7 at.\%. Note that oxidation does not occur up to $400{ }^{\circ} \mathrm{C}(\operatorname{Ref} 60,61)$.

It is established that while scratching a glass using a $500-\mu \mathrm{m}$ radius stainless steel indenter, friction increases with the increase in temperature in the range of $25-400{ }^{\circ} \mathrm{C}$, with stick-slip controlling the response at $400{ }^{\circ} \mathrm{C}$. Such stiction can be attributed to the repetitive formation and following fracture of chromium oxide $\left(\mathrm{CrO}_{2}\right)$ bridges at $400{ }^{\circ} \mathrm{C}$. In contrast, while scratching TiN-based and $\mathrm{Cr}_{54} \mathrm{Al}_{20} \mathrm{C}_{26}$ (MAXphase composition) coatings using a $\mathrm{WC}-\mathrm{Co}$ probe in the temperature range of $25-750{ }^{\circ} \mathrm{C}$, maximum magnitude of friction coefficient occurs at $400{ }^{\circ} \mathrm{C}$. The reduction in friction of TiN-based coating above $400{ }^{\circ} \mathrm{C}$ is attributed to the oxidation of the $\mathrm{Ti}$ interlayer and $\mathrm{TiN}$ coating to produce lubricious $\mathrm{TiO}_{x}$ wear debris. Similarly, the increase in surface roughness of MAX-phase composition at $750{ }^{\circ} \mathrm{C}$ could be somewhat related to surface oxidation (Ref 44). It is of note that there exist some experimental studies showing the increase in friction coefficient with increasing temperature in the temperature range of 65-293 K (Ref 91, 92).

Micro-scratch tests performed on high-temperature scratch test rig developed at the Austrian competence center, shown in Fig. 4, using a Rockwell-C diamond cone, a cone with $120^{\circ}$ opening angle and a $200-\mu \mathrm{m}$ spherical tip radius, reveal that ploughing is the prevailing wear mechanism for the austenite, ferritic metal matrix composites (MMCs) and Ni-based MMCs up to temperature of $500{ }^{\circ} \mathrm{C}$. This mechanism switches to cutting for the Ni-based MMC at $800{ }^{\circ} \mathrm{C}$ for high loads, as shown in Fig. 10(f). Also, it is indicated that, owing to the inhomogeneous microstructure of multiphase materials, they exhibit unstable scratch behavior, which can be intensified with increasing temperature as a result of matrix softening and subsequent carbide displacement (Ref 62).

On a final note, of great interest is the work of He et al. (Ref 63 ) who elaborated on the influence of melting and microstruc- ture on the friction behavior of three silver-bismuth alloys through high-temperature scratching with a Rockwell diamond tip (tip radius $\sim 25 \mu \mathrm{m}$ ). Up to $250{ }^{\circ} \mathrm{C}$ (before melting), ploughing of the scanning tip and, in turn, friction increases with increasing temperature, which is consistent with the Bowden and Tabor models of friction, i.e., as temperature increases so does ploughing usually due to softening (Ref 93). However, at temperatures higher than the eutectic temperature, at which a bismuth-rich liquid phase is formed, the coefficient of friction decreases sharply for two alloys, yet increases steadily with increasing temperature for the third alloy (Fig. 11). The different behavior of friction coefficient can be attributed to the difference in phase composition of the three alloys. According to Ag-Bi phase diagram, a liquid phase is formed at temperatures higher than the eutectic temperature. The composition of alloy 1, i.e., $97.5 \mathrm{wt} . \% \mathrm{Bi}-2.5 \mathrm{wt} . \% \mathrm{Ag}$, is close to the eutectic composition; thus, the percentage of liquid phase is practically $100 \%$. For alloy 2 with the composition of 70 wt. $\%$ Bi-30 wt. $\% A g$, the liquid weight fraction is $\sim 72 \%$. Accordingly, at the eutectic temperature, alloys 1 and 2 have a liquid-like surface with small amounts of solids in isolated islands, triggering the decrease in friction. In contrast, alloy 3 , with the composition of 50 wt. $\% \mathrm{Bi}-50$ wt. $\% \mathrm{Ag}$, has only $50 \%$ liquid phase at the eutectic temperature; hence, the other $50 \%$ comprises of deformable solids (mainly Ag) which might make up the monotonic increase in friction with temperature.

\section{Summary and Outlook}

Micro-/nanoscale mechanical testing techniques open up the possibility of accurately evaluating mechanical and tribological properties of materials and deformation mechanisms at the micro-/nanoscale under different forms of loading. Instrumented micro-/nanoscratching is a popular and flexible mechanical testing method which is widely utilized due to its relatively intrinsic experimental simplicity. On the other hand, the need to comprehend how materials respond to different types of loading and how they behave under high contact pressure sliding/abrasive contacts at the actual temperatures experienced in-service has led to the emergence of the instrumented high-temperature micro- and nanoscratching/tribology technique. Accordingly, aggressive developments in micro- and nanoscratching/tribology instruments capable of performing tests at elevated temperatures and in controlled environments have taken place over the last decade. Nowadays, a variety of high-temperature micro- and nanoscratching/ tribology equipment is commercially available to characterize materials under inert gas purged or vacuum conditions. Nevertheless, there are a few technical challenges in the development of high-temperature micro- and nanoscratching/ tribology techniques since the accurate collection and process of consequential experimental data are significantly sensitive to external test parameters. An important technical issue involves knowledge and control of thermal gradients at high temperatures so as to avoid heat transfer/thermal drift from interfering with measurements. Care must be taken to match the indenter and sample temperatures. Basically, it is indispensable to achieve an isothermal contact at a known temperature in thermal equilibrium for high-temperature micro- and nanoscratching/tribology systems capable of heating the sample and indenter independently. This can be achieved by using the 

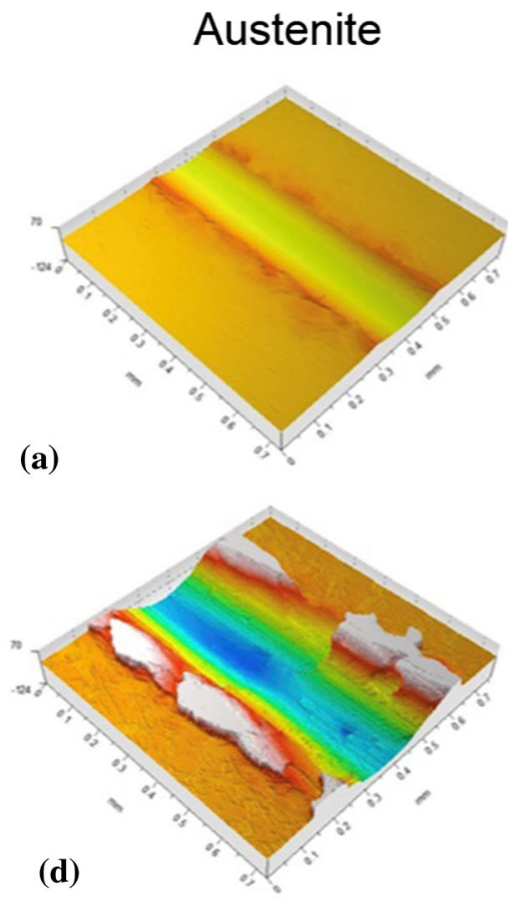

(b)
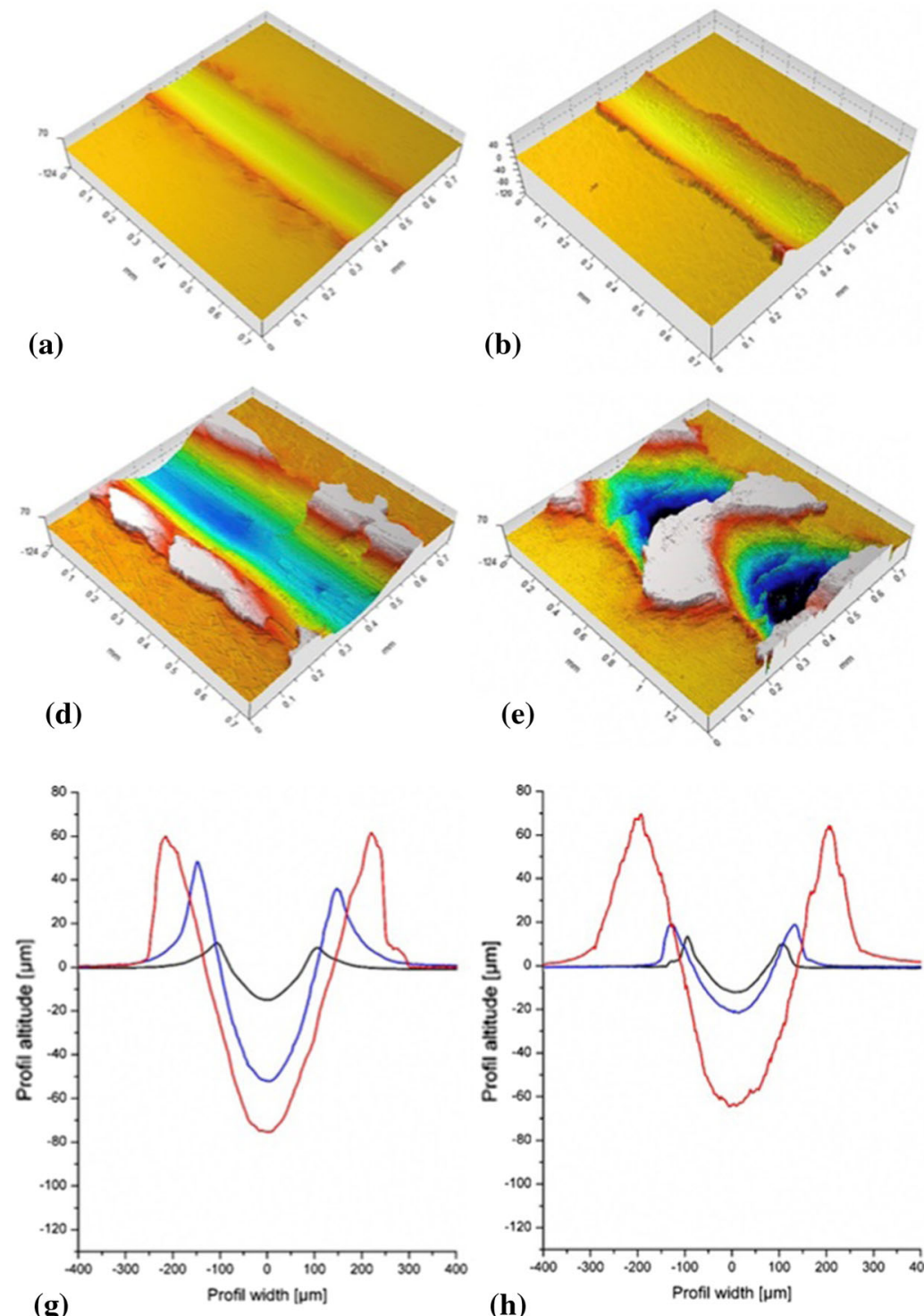

(g)

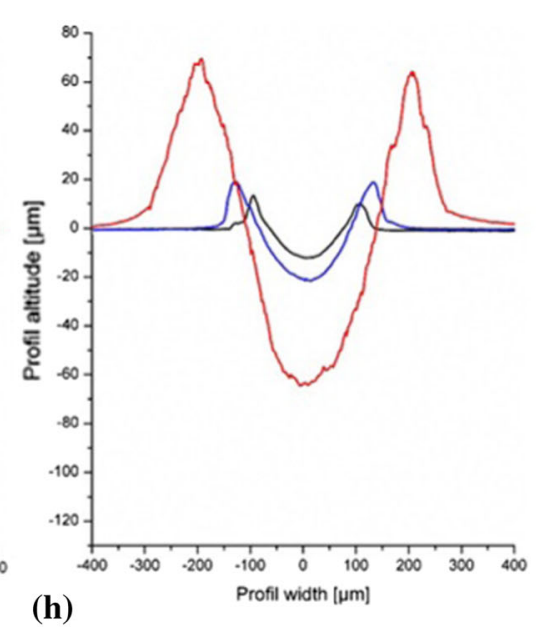

(h)
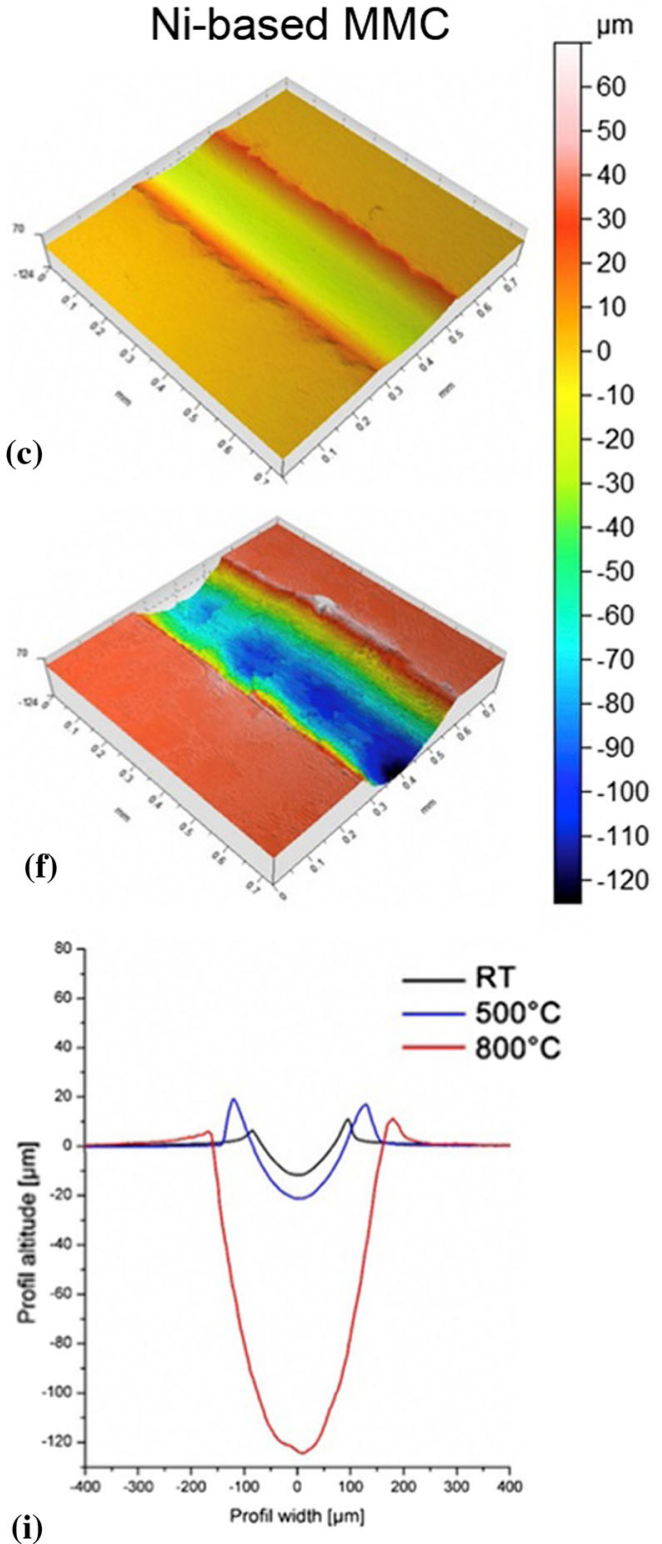

(i)

Fig. 10 Surface topography analyses at (a-c) room temperature (d-f) $800{ }^{\circ} \mathrm{C}$. (g-i) The average profiles of scratches at different temperatures. (Reprinted with permission from Ref 62)

indenter temperature profile during the process as a sensitive and unique signature of the system thermal setup. It is expected that future development of micro- and nanoscratching/tribology will largely feature increased automation of temperature controls and testing. This will enable large test grids of material to be interrogated as a function of size, temperature, and strain rate $(\operatorname{Ref} 35,51)$.

Another notable challenge for micro- and nanoscratching/ tribology at high temperatures is to develop a new indenter material capable of resisting high temperatures without pronounced blunting after only a few tests. Currently, diamond, $\mathrm{cBN}$, and $\mathrm{BC}_{4}$ are the known materials for scratching hard materials at elevated temperatures because of their outstanding preserved hardness at elevated temperatures. In terms of reactivity, diamond is the best option for strong, inert materials such as ceramics, whereas cBN, WC, and sapphire are more suitable in the cases where diamond may unfavorably react with the substrate material at elevated temperatures. In particular, cBN and sapphire tips are popular, even though they are much softer than diamond, because of their low chemical reactivity, immunity to oxidation, low cost, and good machinability. Diamond-like $\mathrm{BC}_{5}$, rhombohedral $\mathrm{B}_{13} \mathrm{~N}_{2}$, and $\mathrm{BC}_{2} \mathrm{~N}$ are other options for indenter materials used for hightemperature applications. However, further justification on their suitability for such applications remains an open question subject to future investigations.

Minimally invasive and nanoscale spatial and spectral measurement capabilities that simultaneously yield mechanical, tribological, thermal, chemical, and electrical mapping within materials are important. A recent surge of interest is geared toward integrating simultaneous nondestructive 3D measurements into micro-/nanoscratching equipment (Ref 94). Although technically challenging (Ref 35,51 ), such in situ high-temperature micro-/nanoscratching measurements are 

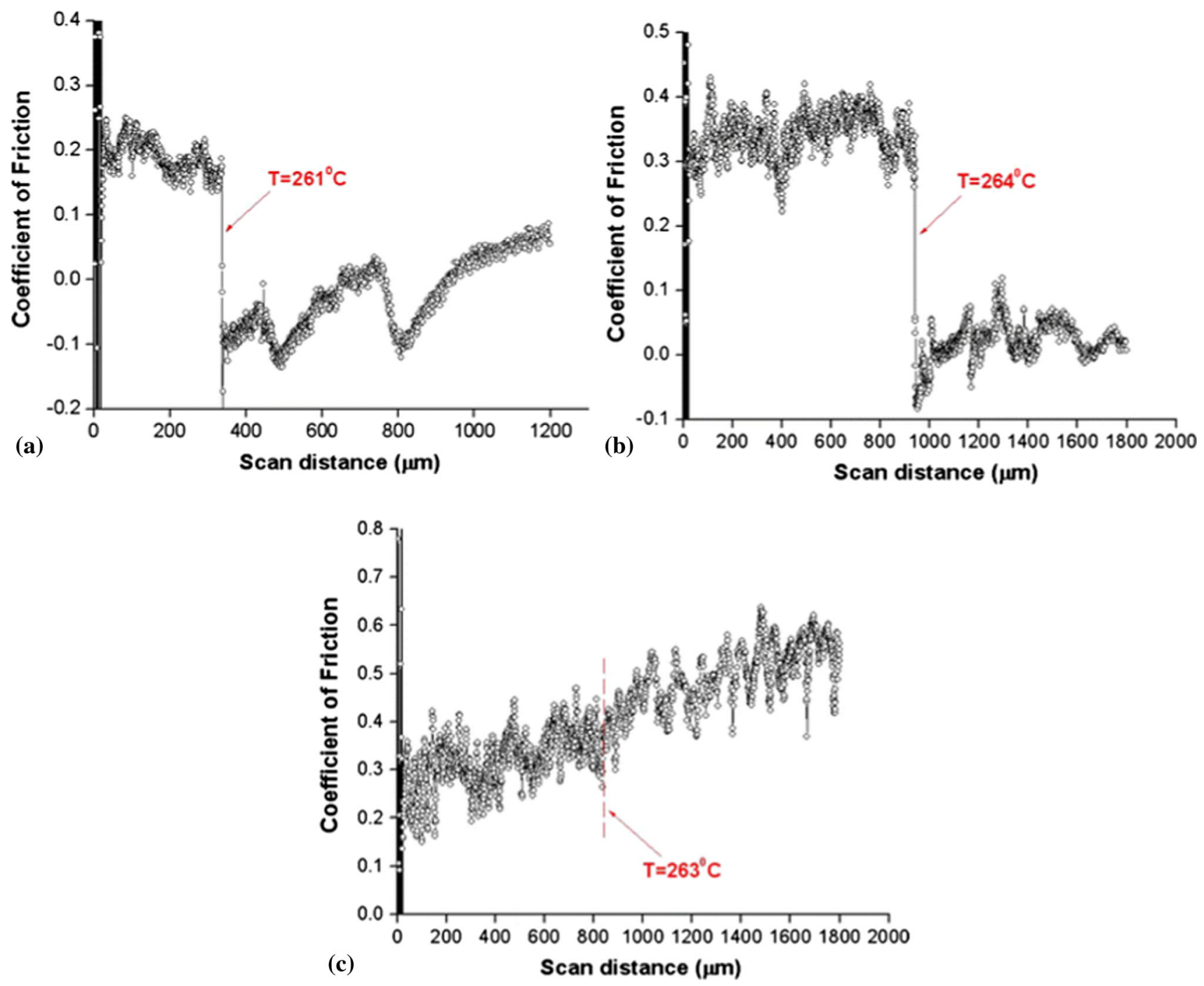

Fig. 11 Variation of friction coefficient with temperature for three Ag-Bi alloys. (a) Alloy 1: 97.5 wt.\%Bi-2.5 wt.\%Ag, (b) alloy 2: 70 wt.\%Bi30 wt.\%Ag, (c) alloy 3: 50 wt.\%Bi-50 wt.\%Ag. (Reprinted with permission from Ref 63)

highly enticing, as the local microstructure properties relations and stress fields with high spatial resolution can be directly observed in "real-time" using, for example, SEM (Ref 40, 76, 77), transmission electron microscopy (TEM) and Raman spectroscopy, yet avoiding unwanted thermal oxidation of samples at elevated temperatures owing to high purged/vacuum conditions. To observe fundamental processes such as nucleation and propagation of dislocations, TEM is unable to attain images with temporal resolution $\sim 1 \mu \mathrm{s}$ to $1 \mathrm{~ns}$. The dynamic transmission electron microscopy (DTEM) (Ref 95) and ultrafast transmission electron microscopy (UTEM) (Ref 96) provide simultaneous nanoscale spatial and temporal resolutions. Integrating high-temperature micro-/nanoscratching with DTEM or UTEM therefore poses promising future endeavors to further enhance the spatial, as well as the temporal, resolution of micro-/nanoscale experimentation. Of particular interest is the use of Bragg coherent diffraction imaging (BCDI) to obtain quantitative 3D images of dislocations (Ref 97) in in situ hightemperature tests, which can outperform electron microscopy. Advanced Raman techniques such as surface-enhanced Raman scattering (SERS) (Ref 98) can be other choices for such integration to perform in situ and nondestructive chemical analysis on surfaces and interfaces with nanometer spatial resolution. High-temperature micro-/nanoscratching combined with in situ electrical characterization (Ref 99-102) can also be developed to probe deformation behavior and electrical properties of materials to the applied forces. Generally, the ability to perform multiple measurements concurrently and combine information from multiple analysis and techniques is highly desirable for micro-/nanoscale material characterization. As a result of the high capability of the in situ measurements, it is envisioned that this arena will be pursued further by researchers in the upcoming years. The use of high-temperature nanoscratching/indentation with combinatorial diffusion multiples (Ref 103) might possibly accelerate the finding of new structural materials and coatings, such as nanocomposite and nanomaterials for high-temperature services (Ref 104).

Challenges exist for achieving lateral rigidity in the nanoindentation and tribometer instruments used for nanotribological experiments. Most modified nanoindentation and tribometer systems have sensitive loading heads, and many have low lateral rigidity which often results in wavy scratch tracks on rough samples. The flexures used in the MML NanoTest and the NPL tribometer can provide a good solution. 
Further efforts are required to improve the lateral rigidity of the nanoindentation and tribometer systems, particularly, in in situ systems which have poor lateral rigidity in general (with the exception of the NPL tribometer).

Some limited experimental evidence promises that tribological systems and superlubricity states around melting temperature are in reach. With the advent of in situ measurement techniques and novel high-temperature micro-/nanoscratching equipment, it is possible to further explore micro-/nanofriction close to the melting temperature and pin down the limits of its applicability, which can open the way to applications in MEMS/NEMS and auto/aerospace engines. Accordingly, further research and development is warranted in the field of near melting temperature micro-/nanotribology. It is worth noting that while many studies (Ref 105-110) have related micro-/nanoscale tribological and scratching behavior to material's microstructure, they are not at high temperatures. Thus, the current pool of knowledge on the topic of microstructural facets of micro-/nanoscale tribology and scratching is quite sparse. With the success of the in situ high-temperature instruments, microstructural issues pose promising future efforts.

As a final point, it is noteworthy that at interfaces of MEMS/ NEMS and other micro-/nanomachines, repetitive contact usually happens; thus, results obtained from a single-pass high-temperature micro-/nanoscratching are not adequate to gain a comprehensive understanding of the deformation mechanisms and tribological behavior of materials systems in such repetitive processes. Arguably, after the first interaction and the generated plastic or damage zone, materials might behave differently under subsequent loadings. Notice that it is demanding to examine cyclic surface plasticity experimentally at the micro-/nanoscale, particularly in the case of accumulation of surface defects during micro-/nanoscale contact (Ref 111). However, recently developed in situ measurements allow identification of surface evolution and damage induced by contact at surfaces under repetitive loading. Deeper understanding of the mechanical response and tribological behavior of materials at elevated temperatures is therefore achieved through performing in situ multi-pass high-temperature micro-/nanoscratching. Notice that repetitive contact in in situ systems, however, culminates in tip wear. There is often a significant benefit in terms of the tip stability in going for micro rather than nano. These factors all make this emerging field a promising area of research with great potential for further exploration.

\section{Acknowledgment}

SZC would like to express his sincere gratitude for the financial support from the BIAM-Imperial Centre for Materials Characterisation, Processing and Modelling at Imperial College London. The work of SX was supported in part by the Elings Prize Fellowship in Science offered by the California NanoSystems Institute (CNSI) on the UC Santa Barbara campus.

\section{References}

1. R.W. Carpick and M. Salmeron, Scratching the Surface: Fundamental Investigations of Tribology with Atomic Force Microscopy, Chem. Rev., 1997, 97, p 1163-1194

2. R. Consiglio, N. Randall, B. Bellaton, and J. Von Stebut, The NanoScratch Tester (NST) as a New Tool for Assessing the Strength of
Ultrathin Hard Coatings and the Mar Resistance of Polymer Films, Thin Solid Films, 1998, 332, p 151-156

3. T. Tsui, G. Pharr, W. Oliver, Y. Chung, E. Cutiongco, C. Bhatia, R. White, R. Rhoades, and S. Gorbatkin, Nanoindentation and Nanoscratching of Hard Coating Materials for Magnetic Disks, MRS Proceedings, Cambridge Univ Press, 1994

4. B. Beake, A. Harris, and T. Liskiewicz, Review of Recent Progress in Nanoscratch Testing, Tribol. Mater. Surf. Interfaces, 2013, 7, p 87-96

5. S.Z. Chavoshi, S. Goel, and X. Luo, Molecular Dynamics Simulation Investigation on the Plastic Flow Behaviour of Silicon During Nanometric Cutting, Modell. Simul. Mater. Sci. Eng., 2015, 24, p 015002

6. S.Z. Chavoshi, S. Goel, and X. Luo, Influence of Temperature on the Anisotropic Cutting Behaviour of Single Crystal Silicon: A Molecular Dynamics Simulation Investigation, J. Manuf. Process., 2016, 23, p 201-210

7. S.Z. Chavoshi and X. Luo, An Atomistic Simulation Investigation on Chip Related Phenomena in Nanometric Cutting of Single Crystal Silicon at Elevated Temperatures, Comput. Mater. Sci., 2016, 113, p $1-10$

8. S.Z. Chavoshi and X. Luo, Molecular Dynamics Simulation Study of Deformation Mechanisms in 3C-SiC During Nanometric Cutting at Elevated Temperatures, Mater. Sci. Eng. A, 2016, 654, p 400-417

9. S.Z. Chavoshi and X. Luo, Atomic-Scale Characterization of Occurring Phenomena During Hot Nanometric Cutting of Single Crystal 3C-SiC, RSC Adv., 2016, 6, p 71409-71424

10. S.Z. Chavoshi, S. Xu, and X. Luo, Dislocation-Mediated Plasticity in Silicon During Nanometric Cutting: A Molecular Dynamics Simulation Study, Mater. Sci. Semicond. Process., 2016, 51, p 60-70

11. S.Z. Chavoshi and S. Xu, Temperature-Dependent Nanoindentation Response of Materials, MRS Commun., 2018, 8, p 15-28

12. A. Vakis, V. Yastrebov, J. Scheibert, C. Minfray, L. Nicola, D. Dini, A. Almqvist, M. Paggi, S. Lee, and G. Limbert, Modeling and Simulation in Tribology Across Scales: An Overview, Tribol. Int., 2018, https://doi.org/10.1016/j.triboint.2018.02.00

13. S.Z. Chavoshi and $\mathrm{S}$. $\mathrm{Xu}$, Nanoindentation/Scratching at Finite Temperatures: Insights from Atomistic-Based Modeling. Submitted, (2018)

14. D. Lucca, K. Herrmann, and M. Klopfstein, Nanoindentation: Measuring Methods and Applications, CIRP Ann. Manuf. Technol., 2010, 59, p 803-819

15. A. Gouldstone, N. Chollacoop, M. Dao, J. Li, A.M. Minor, and Y.-L. Shen, Indentation Across Size Scales and Disciplines: Recent Developments in Experimentation and Modeling, Acta Mater., 2007, 55, p 4015-4039

16. W.C. Oliver and G.M. Pharr, Measurement of Hardness and Elastic Modulus by Instrumented Indentation: Advances in Understanding and Refinements to Methodology, J. Mater. Res., 2004, 19, p 3-20

17. M.R. VanLandingham, Review of Instrumented Indentation, J. Res. Natl. Inst. Stand. Technol., 2003, 108, p 249

18. Y.I. Golovin, Nanoindentation and Mechanical Properties of Solids in Submicrovolumes, Thin Near-Surface Layers, and Films: A Review, Phys. Solid State, 2008, 50, p 2205-2236

19. C.A. Schuh, Nanoindentation Studies of Materials, Mater. Today, 2006, 9, p 32-40

20. X. Li and B. Bhushan, A Review of Nanoindentation Continuous Stiffness Measurement Technique and Its Applications, Mater. Charact., 2002, 48, p 11-36

21. A.C. Fischer-Cripps, Critical Review of Analysis and Interpretation of Nanoindentation Test Data, Surf. Coat. Technol., 2006, 200, p 41534165

22. S.R. Cohen and E. Kalfon-Cohen, Dynamic Nanoindentation by Instrumented Nanoindentation and Force Microscopy: A Comparative Review, Beilstein J. Nanotechnol., 2013, 4, p 815-833

23. E. Broitman, Indentation Hardness Measurements at Macro-, Micro-, and Nanoscale: A Critical Overview, Tribol. Lett., 2017, 65, p 23

24. B. Bhushan and X. Li, Nanomechanical Characterisation of Solid Surfaces and Thin Films, Int. Mater. Rev., 2003, 48, p 125-164

25. A. Atkins and D. Tabor, Hardness and Deformation Properties of Solids at Very High Temperatures, Proceedings of the Royal Society of London A: Mathematical, Physical and Engineering Sciences, The Royal Society, 1966

26. B. Lucas and W. Oliver, Time Dependent Indentation Testing at Nonambient Temperatures Utilizing the High Temperature Mechanical 
Properties Microprobe, MRS Proceedings, Cambridge Univ Press, 1994

27. W. Poisl, W. Oliver, and B. Fabes, The Relationship Between Indentation and Uniaxial Creep in Amorphous Selenium, J. Mater. Res., 1995, 10, p 2024-2032

28. T. Suzuki and T. Ohmura, Ultra-Microindentation of Silicon at Elevated Temperatures, Philos. Mag. A, 1996, 74, p 1073-1084

29. S. Syed Asif and J. Pethica, Nano-scale Indentation Creep Testing at Non-ambient Temperature, J. Adhes., 1998, 67, p 153-165

30. J. Smith and S. Zheng, High Temperature Nanoscale Mechanical Property Measurements, Surf. Eng., 2000, 16, p 143-146

31. A.A. Volinsky, N.R. Moody, and W.W. Gerberich, Nanoindentation of $\mathrm{Au}$ and $\mathrm{Pt} / \mathrm{Cu}$ Thin Films at Elevated Temperatures, J. Mater. Res., 2004, 19, p 2650-2657

32. J.C. Trenkle, C.E. Packard, and C.A. Schuh, Hot Nanoindentation in Inert Environments, Rev. Sci. Instrum., 2010, 81, p 073901-073914

33. I. Cheng, E. Garcia-Sanchez, and A. Hodge, Note: A Method for Minimizing Oxide Formation During Elevated Temperature Nanoindentation, Rev. Sci. Instrum., 2014, 85, p 096106

34. S. Korte, R.J. Stearn, J.M. Wheeler, and W.J. Clegg, High Temperature Microcompression and Nanoindentation in Vacuum, J. Mater. Res., 2012, 27, p 167-176

35. J. Wheeler, D. Armstrong, W. Heinz, and R. Schwaiger, High Temperature Nanoindentation: The State of the Art and Future Challenges, Curr. Opin. Solid State Mater. Sci., 2015, 19, p 354-366

36. N. Everitt, M. Davies, and J. Smith, High Temperature Nanoindentation-The Importance of Isothermal Contact, Philos. Mag., 2011, 91, p 1221-1244

37. H. Lee, Y. Chen, A. Claisse, and C. Schuh, Finite Element Simulation of Hot Nanoindentation in Vacuum, Exp. Mech., 2013, 53, p 12011211

38. J. Wheeler, P. Brodard, and J. Michler, Elevated Temperature, In Situ Indentation with Calibrated Contact Temperatures, Philos. Mag., 2012, 92, p 3128-3141

39. X. Hou, C. Alvarez, and N. Jennett, Establishing Isothermal Contact at a Known Temperature Under Thermal Equilibrium in Elevated Temperature Instrumented Indentation Testing. Meas. Sci. Technol., 2017, 28, p 025016

40. J. Wheeler and J. Michler, Elevated Temperature, Nano-mechanical Testing In Situ in the Scanning Electron Microscope, Rev. Sci. Instrum., 2013, 84, p 045103-045118

41. C.A. Schuh, C.E. Packard, and A.C. Lund, Nanoindentation and Contact-Mode Imaging at High Temperatures, J. Mater. Res., 2006, 21, p 725-736

42. C.E. Packard, J.M. Wheeler, J.C. Trenkle, and C.A. Schuh, Nanoindentation: High Temperature, Ref. Modul. Mater. Sci. Mater. Eng., 2016

43. C. Schuh, J. Mason, A. Lund, and A. Hodge, High Temperature Nanoindentation for the Study of Flow Defects, MRS Proceedings, Cambridge Univ Press, 2004

44. J. Smith, V. Vishnyakov, M. Davies, and B. Beake, Nanoscale Friction Measurements Up to $750{ }^{\circ} \mathrm{C}$, Tribol. Lett., 2013, 49, p $455-$ 463

45. M. Varga, M. Flasch, and E. Badisch, Introduction of a Novel Tribometer Especially Designed for Scratch, Adhesion and Hardness Investigation Up to $1000{ }^{\circ} \mathrm{C}$, Proc. Inst. Mech. Eng. Part J J. Eng. Tribol., 2017, 231, p 469-478

46. S. Leroch, M. Varga, S. Eder, A. Vernes, M.R. Ripoll, and G. Ganzenmüller, Smooth Particle Hydrodynamics Simulation of Damage Induced by a Spherical Indenter Scratching a Viscoplastic Material, Int. J. Solids Struct., 2016, 81, p 188-202

47. S. Smith, D. Chetwynd, and D. Bowen, Design and Assessment of Monolithic High Precision Translation Mechanisms, J. Phys. E Sci. Instrum., 1987, 20, p 977

48. M. Gee, J. Nunn, A. Muniz-Piniella, and L. Orkney, Micro-tribology Experiments on Engineering Coatings, Wear, 2011, 271, p 2673-2680

49. A. Gant, J. Nunn, M. Gee, D. Gorman, D. Gohil, and L. Orkney, New Perspectives in Hardmetal Abrasion Simulation, Wear, 2017, 376, p $2-14$

50. J. Wheeler and J. Michler, Invited Article: Indenter Materials for High Temperature Nanoindentation, Rev. Sci. Instrum., 2013, 84, p 101301

51. W. Kang, M. Merrill, and J.M. Wheeler, In Situ Thermomechanical Testing Methods for Micro/Nano-scale Materials, Nanoscale, 2017, 9 , p 2666
52. S.Z. Chavoshi, S.C. Gallo, H. Dong, and X. Luo, High Temperature Nanoscratching of Single Crystal Silicon Under Reduced Oxygen Condition, Mater. Sci. Eng. A, 2017, 684, p 385-393

53. H. Mohammadi, D. Ravindra, S.K. Kode, and J.A. Patten, Experimental Work on Micro Laser-Assisted Diamond Turning of Silicon (111), J. Manuf. Process., 2015, 19, p 125-128

54. J. Pujante, M. Vilaseca, D. Casellas, and M.D. Riera, High Temperature Scratch Testing of Hard PVD Coatings Deposited on Surface Treated Tool Steel, Surf. Coat. Technol., 2014, 254, p 352357

55. J. Batista, C. Godoy, V. Buono, and A. Matthews, Characterisation of Duplex and Non-duplex (Ti, Al) N and Cr-N PVD Coatings, Mater. Sci. Eng. A, 2002, 336, p 39-51

56. J. Batista, C. Godoy, G. Pintaúde, A. Sinatora, and A. Matthews, An Approach to Elucidate the Different Response of PVD Coatings in Different Tribological Tests, Surf. Coat. Technol., 2003, 174, p 891898

57. D. Allsopp and I. Hutchings, Micro-scale Abrasion and Scratch Response of PVD Coatings at Elevated Temperatures, Wear, 2001, 251, p 1308-1314

58. G. Fox-Rabinovich, J. Endrino, B. Beake, A. Kovalev, S. Veldhuis, L. Ning, F. Fontaine, and A. Gray, Impact of Annealing on Microstructure, Properties and Cutting Performance of an AlTiN Coating, Surf. Coat. Technol., 2006, 201, p 3524-3529

59. G. Fox-Rabinovich, B. Beake, J. Endrino, S. Veldhuis, R. Parkinson, L. Shuster, and M. Migranov, Effect of Mechanical Properties Measured at Room and Elevated Temperatures on the Wear Resistance of Cutting Tools with TiAlN and AlCrN Coatings, Surf. Coat. Technol., 2006, 200, p 5738-5742

60. W. Tillmann, D. Kokalj, D. Stangier, M. Paulus, C. Sternemann, and M. Tolan, Investigation on the Oxidation Behavior of AlCrVxN Thin Films by Means of Synchrotron Radiation and Influence on the High Temperature Friction, Appl. Surf. Sci., 2018, 427, p 511-521

61. W. Tillmann, D. Kokalj, D. Stangier, M. Paulus, C. Sternemann, and M. Tolan, Investigation of the Influence of the Vanadium Content on the High Temperature Tribo-Mechanical Properties of DC Magnetron Sputtered AlCrVN Thin Films, Surf. Coat. Technol., 2017, 328, p 172-181

62. M. Varga, S. Leroch, H. Rojacz, and M.R. Ripoll, Study of Wear Mechanisms at High Temperature Scratch Testing, Wear, 2017, 388, p 112

63. B. He, G. Ghosh, Y.-W. Chung, and Q. Wang, Effect of Melting and Microstructure on the Microscale Friction of Silver-Bismuth Alloys, Tribol. Lett., 2010, 38, p 275-282

64. H. Rojacz, G. Mozdzen, F. Weigel, and M. Varga, Microstructural Changes and Strain Hardening Effects in Abrasive Contacts at Different Relative Velocities and Temperatures, Mater. Charact., 2016, 118, p 370-381

65. J. Williams, Analytical Models of Scratch Hardness, Tribol. Int., 1996, 29, p 675-694

66. S. Graça, R. Colaço, and R. Vilar, Micro-to-nano Indentation and Scratch Hardness in the Ni-Co System: Depth Dependence and Implications for Tribological Behavior, Tribol. Lett., 2008, 31, p 177

67. V. Domnich, Y. Aratyn, W.M. Kriven, and Y. Gogotsi, Temperature Dependence of Silicon Hardness: Experimental Evidence of Phase Transformations, Rev. Adv. Mater. Sci., 2008, 17, p 33-41

68. S. Ruffell, J. Bradby, and J.S. Williams, Annealing Kinetics of Nanoindentation-Induced Polycrystalline High Pressure Phases in Crystalline Silicon, Appl. Phys. Lett., 2007, 90, p 131901-131904

69. Z. Zeng, Q. Zeng, W.L. Mao, and S. Qu, Phase Transitions in Metastable Phases of Silicon, J. Appl. Phys., 2014, 115, p 103514 103520

70. Y.B. Gerbig, C. Michaels, J.E. Bradby, B. Haberl, and R.F. Cook, In Situ Spectroscopic Study of the Plastic Deformation of Amorphous Silicon Under Nonhydrostatic Conditions Induced by Indentation, Phys. Rev. B, 2015, 92, p 214110

71. Y.B. Gerbig, C.A. Michaels, and R.F. Cook, In Situ Observation of the Spatial Distribution of Crystalline Phases During PressureInduced Transformations of Indented Silicon Thin Films, J. Mater. Res., 2015, 30, p 390-406

72. Y. Gerbig, C. Michaels, A. Forster, J. Hettenhouser, W. Byrd, D. Morris, and R. Cook, Indentation Device for In Situ Raman Spectroscopic and Optical Studies, Rev. Sci. Instrum., 2012, 83, p 125106 
73. Y.B. Gerbig, C.A. Michaels, and R.F. Cook, In Situ Observations of Berkovich Indentation Induced Phase Transitions in Crystalline Silicon Films, Scripta Mater., 2016, 120, p 19-22

74. Y. Gerbig, C. Michaels, A. Forster, and R. Cook, In Situ Observation of the Indentation-Induced Phase Transformation of Silicon Thin Films, Phys. Rev. B, 2012, 85, p 104102

75. P. Manimunda, E. Hintsala, S. Asif, and M.K. Mishra, Mechanical Anisotropy and Pressure Induced Structural Changes in Piroxicam Crystals Probed by In Situ Indentation and Raman Spectroscopy, JOM, 2017, 69, p 57-63

76. J. Wheeler, C. Niederberger, C. Tessarek, S. Christiansen, and J. Michler, Extraction of Plasticity Parameters of $\mathrm{GaN}$ with High Temperature, In Situ Micro-Compression, Int. J. Plast., 2013, 40, p 140-151

77. J. Wheeler, R. Raghavan, and J. Michler, In Situ SEM Indentation of a Zr-Based Bulk Metallic Glass at Elevated Temperatures, Mater. Sci. Eng. A, 2011, 528, p 8750-8756

78. B. Bhushan, Nanotribology and Nanomechanics, Wear, 2005, 259, p 1507-1531

79. C. Cheung and W. Lee, Characterisation of Nanosurface Generation in Single-Point Diamond Turning, Int. J. Mach. Tools Manuf., 2001, 41, p 851-875

80. T.G. Bifano, T. Dow, and R. Scattergood, Ductile-Regime Grinding: A New Technology for Machining Brittle Materials, J. Eng. Ind., 1991, 113, p 184-189

81. P.N. Blake and R.O. Scattergood, Ductile-Regime Machining of Germanium and Silicon, J. Am. Ceram. Soc., 1990, 73, p 949-957

82. J. Patten, W. Gao, and K. Yasuto, Ductile Regime Nanomachining of Single-Crystal Silicon Carbide, J. Manuf. Sci. Eng., 2005, 127, p 522-532

83. S.Z. Chavoshi and X. Luo, Hybrid Micro-machining Processes: A Review, Precis. Eng., 2015, 41, p 1-23

84. S.Z. Chavoshi, S. Goel, and P. Morantz, Current Trends and Future of Sequential Micro-machining Processes on a Single Machine Tool, Mater. Des., 2017, 127, p 37-53

85. D. Ravindra, Ductile Mode Material Removal of Ceramics and Semiconductors, Department of Mechanical and Aeronautical Engineering, Western Michigan University, Michigan, 2011, p 312

86. D. Ravindra, M.K. Ghantasala, and J. Patten, Ductile Mode Material Removal and High-Pressure Phase Transformation in Silicon During Micro-laser Assisted Machining, Precis. Eng., 2012, 36, p 364-367

87. D. Ravindra and J.A. Patten, Chapter 4: Ductile Regime Material Removal of Silicon Carbide(SiC), Silicon Carbide: New Materials, Production Methods and Application, S.H. Vanger, Ed., Nova Publishers, Trivandrum, 2011, p 141-167

88. A.R. Shayan, H.B. Poyraz, D. Ravindra, M. Ghantasala, and J.A. Patten. Force Analysis, Mechanical Energy and Laser Heating Evaluation of Scratch Tests on Silicon Carbide (4H-SiC) in MicroLaser Assisted Machining ( $\mu$-LAM) Process, ASME 2009 International Manufacturing Science and Engineering Conference. American Society of Mechanical Engineers, 2009

89. H. Mohammadi and J.A. Patten, Effect of Thermal Softening on Anisotropy and Ductile Mode Cutting of Sapphire Using Micro-laser Assisted Machining, J. Micro Nano Manuf., 2017, 5, p 011007

90. B. Beake, J. Endrino, C. Kimpton, G. Fox-Rabinovich, and S. Veldhuis, Elevated Temperature Repetitive Micro-scratch Testing of AlCrN, TiAlN and AlTiN PVD Coatings, Int. J. Refract. Metal. Hard Mater., 2017, 69, p 215-226

91. I. Altfeder and J. Krim, Temperature Dependence of Nanoscale Friction for Fe on YBCO, J. Appl. Phys., 2012, 111, p 094916

92. C. Dunckle, I. Altfeder, A. Voevodin, J. Jones, J. Krim, and P. Taborek, Temperature Dependence of Single-Asperity Friction for a Diamond on Diamondlike Carbon Interface, J. Appl. Phys., 2010 , 107, p 114903
93. F.P. Bowden and D. Tabor, The Friction and Lubrication of Solids, Vol 1, Oxford University Press, Oxford, 2001

94. H. Nili, K. Kalantar-zadeh, M. Bhaskaran, and S. Sriram, In Situ Nanoindentation: Probing Nanoscale Multifunctionality, Prog. Mater Sci., 2013, 58, p 1-29

95. N. Browning, M. Bonds, G. Campbell, J. Evans, T. LaGrange, K. Jungjohann, D. Masiel, J. McKeown, S. Mehraeen, and B. Reed, Recent Developments in Dynamic Transmission Electron Microscopy, Curr. Opin. Solid State Mater. Sci., 2012, 16, p 2330

96. A. Feist, N. Bach, N.R. da Silva, T. Danz, M. Möller, K.E. Priebe, T. Domröse, J.G. Gatzmann, S. Rost, and J. Schauss, Ultrafast Transmission Electron Microscopy Using a Laser-Driven Field Emitter: Femtosecond Resolution with a High Coherence Electron Beam, Ultramicroscopy, 2017, 176, p 63-73

97. M. Dupraz, G. Beutier, T. Cornelius, G. Parry, Z. Ren, S. Labat, M.-I. Richard, G. Chahine, O. Kovalenko, and M. De Boissieu, 3D Imaging of a Dislocation Loop at the Onset of Plasticity in an Indented Nanocrystal, Nano Lett., 2017, 17, p 6696

98. P.L. Stiles, J.A. Dieringer, N.C. Shah, and R.P. Van Duyne, SurfaceEnhanced Raman Spectroscopy, Annu. Rev. Anal. Chem., 2008, 1, p 601-626

99. J. Bradby, J. Williams, and M.V. Swain, In Situ Electrical Characterization of Phase Transformations in Si During Indentation, Phys. Rev. B, 2003, 67, p 085205

100. N. Fujisawa, S. Ruffell, J. Bradby, J. Williams, B. Haberl, and O. Warren, Understanding Pressure-Induced Phase-Transformation Behavior in Silicon Through In Situ Electrical Probing Under Cyclic Loading Conditions, AIP, 2009, 105, p 106111

101. S. Ruffell, J. Bradby, J. Williams, and O. Warren, An In Situ Electrical Measurement Technique Via a Conducting Diamond Tip For Nanoindentation in Silicon, J. Mater. Res., 2007, 22, p 578-586

102. S. Ruffell, J. Bradby, N. Fujisawa, and J. Williams, Identification of Nanoindentation-Induced Phase Changes in Silicon by In Situ Electrical Characterization, J. Appl. Phys., 2007, 101, p 083531

103. J.-C. Zhao, The Diffusion-Multiple Approach To Designing Alloys, Annu. Rev. Mater. Res., 2005, 35, p 51-73

104. A. Sawant and S. Tin, High Temperature Nanoindentation of a ReBearing Single Crystal Ni-Base Superalloy, Scripta Mater., 2008, 58, p $275-278$

105. T. Csanádi, M. Novák, A. Naughton-Duszová, and J. Dusza, Anisotropic Nanoscratch Resistance of WC Grains in WC-Co Composite, Int. J. Refract. Metal. Hard Mater, 2015, 51, p 188-191

106. M. Gee, K. Mingard, J. Nunn, B. Roebuck, and A. Gant, In Situ Scratch Testing and Abrasion Simulation of WC/Co, Int. J. Refract. Metal. Hard Mater., 2017, 62, p 192-201

107. L. Joly-Pottuz, E. Bucholz, N. Matsumoto, S. Phillpot, S. Sinnott, N. Ohmae, and J. Martin, Friction Properties of Carbon Nano-onions from Experiment and Computer Simulations, Tribol. Lett., 2010, 37, p 75

108. A. Samanta, H. Chakraborty, M. Bhattacharya, J. Ghosh, M. Sreemany, S. Bysakh, R. Rane, A. Joseph, G. Jhala, and S. Mukherjee, Nanotribological Response of a Plasma Nitrided BioSteel, J. Mech. Behav. Biomed. Mater, 2017, 65, p 584-599

109. A. Samanta, M. Bhattacharya, I. Ratha, H. Chakraborty, S. Datta, J. Ghosh, S. Bysakh, M. Sreemany, R. Rane, and A. Joseph, Nano-and Micro-Tribological Behaviours of Plasma Nitrided Ti6Al4V Alloys, $J$. Mech. Behav. Biomed. Mater., 2018, 77, p 267-294

110. S. Brinckmann and G. Dehm, Nanotribology in Austenite: Plastic Plowing and Crack Formation, Wear, 2015, 338, p 436-440

111. B. Shiari and R.E. Miller, Multiscale Modeling of Ductile Crystals at the Nanoscale Subjected to Cyclic Indentation, Acta Mater., 2008, 56, p 2799-2809 